\title{
Modelling of organic Rankine cycle efficiency with respect to the equivalent hot side temperature
}

\author{
Jing Li ${ }^{1}$, Jahan Zeb ${ }^{1}$ Alvi, Gang Pei ${ }^{1 *}$, Yuehong $\mathrm{Su}^{2}$, Pengcheng Li ${ }^{1}$, Guangtao Gao ${ }^{1}$, \\ Jie $\mathbf{J i}^{\mathbf{1}}$ \\ ${ }^{1}$ Department of Thermal Science and Energy Engineering, University of Science and \\ Technology of China, 96 Jinzhai Road ,Hefei, China \\ ${ }^{2}$ Institute of Sustainable Energy Technology, University of Nottingham, University Park, \\ Nottingham NG7 2RD, UK
}

Abstract: An indicator, namely equivalent hot side temperature ( $\mathrm{T}_{\mathrm{EHST}}$ ) is proposed for the organic Rankine cycle (ORC). TEHST is derived from ideal thermodynamic process, but can denote the efficiency of irreversible ORC. Study on 27 fluids shows that given the operating conditions, fluid of higher $\mathrm{T}_{\mathrm{EHST}}$ generally offers higher ORC efficiency. This relationship is stronger and more universal than those established with respect to the critical temperature, boiling point temperature, Jacobs number and Figure of Merit. An ORC model by the method of error transfer and compensation is further built, in which the efficiency is quantitatively correlated with $\mathrm{T}_{\mathrm{EHST}}$. Unlike the conventional ORC efficiency model, this one consists of thermodynamic parameters on the liquid/vapor curve and is independent on fluid properties at superheated state, and hence is more convenient. It has high accuracy especially for basic ORC and the relative deviation of the estimated efficiency from that calculated by the conventional model is from $-0.7 \%$ to $3.4 \%$. The novel model is applied for the thermodynamic performance prediction of a recently developed fluid of HFO1336mzzZ based on the phase equilibrium data. The results indicate HFO1336mzzZ is more efficient than R245fa on the conditions of high evaporation temperature and low 
pump efficiency.

Keywords: organic Rankine cycle; equivalent hot side temperature; efficiency indicator; liquid-vapor equilibrium; error

*Corresponding author. Tel./Fax: +86 551 63607367. E-mail: peigang@ustc.edu.cn.

\section{Introduction}

Organic Rankine cycle (ORC) has been proven to be one of the most promising and efficient technologies for converting low-grade heat e.g. solar thermal energy, geothermal energy, industrial waste heat, biomass energy and ocean thermal energy into electricity[1, 2]. In the past decade, effect of working fluid on the performance of the ORC system has been studied intensively. Different indicators have been proposed such as vapor density, liquid specific heat, molecular entropy, enthalpy ratio, boiling point temperature, critical temperature, Jacobs number and Figure of Merit (FOM). These indicators are good guidelines for the ORC performance assessment.

Low vapor density is accompanied by high volume flow rate which leads to large pressure drop across the heat exchanger. The size of the expander must be also increased which significantly affects the cost of the system [3, 4]. Low liquid specific heat of the working fluid can decrease work done by the pump and increase work output indirectly [3, 5, 6]. For subcritical ORC systems, fluids having lower molecular entropies result in higher thermal efficiencies [7]. The effect of the boiling point temperature of working fluids on the ORC performance has been investigated, and higher boiling point temperature causes higher evaporation pressure [8]. Enthalpy ratio (ratio of the latent heat of vaporization to the sensible heat) strongly influences the energetic and exergetic efficiency of ORC system. 
Higher enthalpy ratio elevates the amount of heat during phase change process. Hence, higher ORC efficiency is achieved while avoiding superheat and regeneration [9].

Jacobs number has been proposed [10], which is correlated to the latent and sensible heat.

$$
J a=C_{p} d T / H v
$$

where $C_{p} d T$ is the sensible heat and $H v$ is the vaporization latent heat. Thermal efficiency of the ORC system decreases with the increment in Jacobs number. A dimensionless FOM combining Jacobs number, evaporation temperature and condensation temperature has been further put forward by Kuo et al [11]. Similarly, thermal efficiency decreases with the increment in FOM.

$$
\text { Figure of Merit }=J a^{0.1}\left(\frac{T_{\text {cond }}}{T_{\text {evp }}}\right)
$$

Among the properties of the working fluid, the critical temperature is one of the most relevant indicators that affect the thermodynamic performance of ORC. The influence of fluid critical temperature on the efficiencies of isolated ORC [8, 12, 13], geothermal ORC [14], waste heat recovery $[8,15,16]$ and solar ORC [3] has been evaluated by lots of researchers. More efficient power conversion can be facilitated by using fluid of higher critical temperature. This conclusion is applicable for most working fluids.

Besides, extensive investigation has been performed on the resultant role of working fluid properties in the net power output [17-19], ratio of power output to heat exchanger area [20,21], net output per unit mass flow rate [22], installation cost per net power output [23-27], exergy efficiency [28-32] and overall system performance [33-35]. 
The aforementioned indicators are linked with the ORC behavior. They make the working fluid selection more commodious. However, the quantitative relationship between the ORC efficiency and these indicators is lacked. In the present study, an equivalent hot side temperature ( $\mathrm{T}_{\mathrm{EHST}}$ ) is proposed. It is a new indicator rooted in the fundamental of thermodynamics. The effect of $\mathrm{T}_{\mathrm{EHST}}$ on the ORC efficiency is examined on various operating conditions. A mathematical model of the ORC efficiency in view of $\mathrm{T}_{\mathrm{EHST}}$ is further established. This model can overcome some disadvantages of the conventional ORC efficiency model. For the latter, thermodynamic information (enthalpy, entropy, et al.) on expander outlet must be known in order to ascertain the cycle efficiency. The parameters at superheated state are correlated with the fluid PVT (pressure-volumetemperature) behavior. It is a cumbersome process to get accurate PVT behavior in a wide range of temperature and pressure. Many fluids especially newly developed fluids are unavailable in commercial database such as REFPROP and CoolProp. Their ORC efficiencies cannot be predicted in a convenient way using the traditional model. For the novel model, only thermodynamic parameters at liquid-vapor equilibrium state are involved. The enthalpy and entropy at superheated state are dispensable. The deduction, accuracy and applicability of the model are investigated in the following sections.

Twenty-seven dry and isentropic working fluids are selected. For dry fluids, optimum ORC efficiency can be achieved since they operate along the saturation vapor curve without being superheated [36-38]. Similarly, in case of an isentropic fluid a nearly vertical vapor saturation curve can be obtained. Vapor remains saturated till the end of expansion process and there is no need for regeneration [39].

\section{Derivation of the equivalent hot side temperature}


The $T$-s diagram of ORC is depicted in Fig.1. An ideal ORC cycle (1-2s-3-4s-1) is comprised by four basic processes: (1) isentropic pressurization by the pump; (2) isobaric heating in the evaporator; (3) isentropic expansion through the expander; (4) isobaric cooling in the condenser.

Thermal efficiency of the ideal ORC is expressed by

$$
\eta_{t, i d}=1-\frac{q_{o, i d}}{q_{i, i d}}
$$

The input and output heat are equal to

$$
\begin{aligned}
q_{i, i d} & =\int_{2 s}^{3} T d s=h_{3}-h_{2 s} \\
q_{o, i d} & =\int_{1}^{4 s} T d s=h_{4 s}-h_{1}
\end{aligned}
$$

The equivalent hot side temperature is determined by

$$
T_{E H S T}=\frac{q_{i, i d}}{\Delta s}=\frac{h_{3}-h_{2 s}}{s_{3}-s_{2 s}}
$$

$\mathrm{T}_{\text {EHST }}$ has a physical meaning. A higher $\mathrm{T}_{\mathrm{EHST}}$ represents a stronger force driving the ORC. Analogously, the equivalent cold side temperature is

$$
T_{E C S T}=\frac{q_{o, i d}}{\Delta s}=\frac{h_{4 s}-h_{1}}{s_{4 s}-s_{1}}
$$

Therefore, with $S_{3}=S_{4 s}$ and $S_{1}=S_{2 s}$, the ORC thermal efficiency can be calculated by

$$
\eta_{t, i d}=1-T_{E C S T} / T_{E H S T}
$$

Most ORC fluids at liquid state are not compressible and most of the heat is taken out by the condensation process. Therefore,

$$
h_{2 s} \approx h_{1}+v_{1}\left(p_{2 s}-p_{1}\right)
$$




$$
\begin{gathered}
T_{E C S T} \approx T_{1} \\
T_{E H S T}=\frac{h_{3}-h_{2 s}}{s_{3}-s_{2 s}} \approx \frac{h_{3}-h_{1}-v_{1}\left(p_{3}-p_{1}\right)}{s_{3}-s_{1}}
\end{gathered}
$$

The right side of Eq.(11) consists of specific enthalpy, specific entropy, specific volume and pressure on the saturation liquid/vapor curve. $p_{3}, h_{3}$ and $s_{3}$ are pressure, specific enthalpy and entropy of the saturation vapor at $T_{3}$, respectively, while $s_{1}, p_{1}, h_{1}$ and $v_{1}$ are the parameters of the saturation liquid at $T_{1}$. Given a fluid, $\mathrm{T}_{\mathrm{EHST}}$ is a function of the evaporation temperature $\left(T_{3}\right)$ and condensation temperature $\left(T_{1}\right)$. $T_{1}$ is generally subject to the environment temperature and ranges from $20^{\circ} \mathrm{C}$ to $40^{\circ} \mathrm{C}$, so $\mathrm{T}_{\text {EHST }}$ is mainly determined by $T_{3}$.

It is easy to establish database on $T_{\text {EHST. }}$ A sample is presented in Table $1 . T_{1}$ is $30^{\circ} \mathrm{C} . T_{3}$ varies from $100{ }^{\circ} \mathrm{C}$ to $150{ }^{\circ} \mathrm{C}$. The fluids are listed in sequence of critical temperature. Benzene has the highest critical temperature of $288.9^{\circ} \mathrm{C}$, while R227ea has the lowest one of $101.7^{\circ} \mathrm{C}$. Only subcritical ORC is considered. With $\mathrm{T}_{\mathrm{EHST}}$, the ORC efficiency can be estimated as shown below.

\section{New models for the ORC}

\subsection{Irreversible ORC efficiency with respect to $\mathrm{T}_{\mathrm{EHST}}$}

A practical ORC (1-2-3-4-1) regarding the thermodynamic irreversibility in the expander, pump and generator has the thermal efficiency as expressed by

$$
\begin{gathered}
\eta_{t}=\frac{w_{e, i d} \cdot \varepsilon_{e} \cdot \varepsilon_{g}-w_{p, i d} / \varepsilon_{p}}{q_{i}} \\
w_{e, i d}=h_{3}-h_{4 s}
\end{gathered}
$$




$$
\begin{gathered}
w_{p, i d}=h_{2 s}-h_{1} \\
q_{i}=h_{3}-h_{2}
\end{gathered}
$$

Notably, to obtain the output power in an ideal expansion process, enthalpy at the expander outlet shall be known. In this work, a more convenient equation is developed and the relationship between $\eta_{t}$ and $T_{E H S T}$ is deduced.

$$
\eta_{t, i d}=\frac{w_{e, i d}-w_{p, i d}}{q_{i, i d}}=\frac{w_{e, i d}(1-a)}{q_{i, i d}}
$$

where $a$ is the ratio of pump power to expander power.

$$
a=\frac{w_{p, i d}}{w_{e, i d}}
$$

$h_{2}-h_{2 s}$ is generally far less than $q_{i}$. Therefore,

$$
\begin{gathered}
q_{i} \approx q_{i, i d} \\
\eta_{t}=\frac{w_{e, i d} \cdot \varepsilon_{e} \cdot \varepsilon_{g}-a \cdot w_{e, i d} / \varepsilon_{p}}{q_{i}} \\
=\frac{w_{e, i d}\left(\varepsilon_{e} \cdot \varepsilon_{g}-a / \varepsilon_{p}\right)}{q_{i}} \\
\approx \eta_{t, i d} \frac{\varepsilon_{e} \cdot \varepsilon_{g}-a / \varepsilon_{p}}{1-a}
\end{gathered}
$$

The ORC efficiency is achieved by combing Eqs. (8) and (19)

$$
\eta_{t} \approx\left(1-\frac{T_{E C S T}}{T_{E H S T}}\right) \cdot \frac{\varepsilon_{e} \cdot \varepsilon_{g}-a / \varepsilon_{p}}{1-a}
$$

\subsection{Ratio of pump power to expander power ( $a$-value)}

The technical work during an ideal expansion is calculated by

$$
w_{e, i d}=-\int_{3}^{4 s} v d p
$$


The integration path is $L_{3 \rightarrow 4 s}$ as depicted by the dash red line in Fig.1.

Assuming the specific volume of saturated vapor $\left(v_{s}\right)$ at a given pressure of $p$ is approximately equal to $v$ in the ideal expansion process,

$$
\left.\left.v_{s}\right|_{p} \approx v\right|_{p}
$$

A reference expander power is then expressed by

$$
w_{r}=-\int_{3}^{4^{\prime}} v_{s} d p
$$

The integration path is $L_{3 \rightarrow 4^{\prime}}$ as depicted by the dash blue line in Fig.1. $w_{r}$ differs from $w_{e, i d}$ because $v$ in Eq.(21) is usually larger than $v_{s}$ in Eq.(23) for each $p$ owing to a degree of superheat along $3 \rightarrow 4$ s. For example, if $T_{4 s} / T_{4^{\prime}}=333 / 303$ then $v_{4 s} / v_{4^{\prime}} \approx 1.1$ based on the ideal gas state equation. Difference between $w_{r}$ and $w_{e, i d}$ exists, and $w_{r}$ is expected to be lower than $w_{e, i d}$. For an approximation,

$$
w_{e, i d} \approx w_{r}
$$

$a$ can be modelled as

$$
a \approx \frac{w_{p, i d}}{w_{r}} \approx \frac{v_{1}\left(p_{3}-p_{1}\right)}{-\int_{3}^{4} v_{s} d p}
$$

The relationship $p=f(T)$ between saturation vapor pressure and temperature can be determined by the Antoine Equation (Eq.26) or Wagner Equation (Eq.27) or modified Riedel Equation (Eq.29),

$$
\log _{10}(p)=A-\frac{B}{T+C}
$$




$$
\begin{gathered}
\ln \frac{p}{p_{c}}=\frac{T_{c}}{T}\left(A_{1} \tau+A_{2} \tau^{1.5}+A_{3} \tau^{2.5}+A_{4} \tau^{5}\right) \\
\tau=\frac{T_{c}-T}{T_{c}} \\
\ln p=A^{\prime}+B^{\prime} / T+C^{\prime} \ln T+D^{\prime} T^{2}+E^{\prime} / T^{2}
\end{gathered}
$$

The saturation liquid and vapor densities of the HCFO and fluorobutene compounds can be estimated by the scaling law and the law of rectilinear diameters [40, 41].

$$
\begin{gathered}
\rho^{L}-\rho^{V}=M \tau^{\beta} \\
\rho^{L}+\rho^{V}=2\left(\rho_{c}+N \tau\right)
\end{gathered}
$$

By combining Eqs. (26)-(31), $\int_{3}^{4^{\prime}} v_{s} d p$ is achieved.

\subsection{New ORC efficiency model by approximating TECST and $a$-value}

With Eqs.(10), (20) and (25), a new ORC efficiency model is built

$$
\eta_{t} \approx\left(1-\frac{T_{1}}{T_{E H S T}}\right) \cdot \frac{\varepsilon_{e} \cdot \varepsilon_{g}+v_{1}\left(p_{3}-p_{1}\right) /\left(\varepsilon_{p} \int_{3}^{4^{\prime}} v_{s} d p\right)}{1+v_{1}\left(p_{3}-p_{1}\right) / \int_{3}^{4^{\prime}} v_{s} d p}
$$

Similarly with $T_{E H S T}, \eta_{t}$ is comprised of thermodynamic parameters at liquid-vapor equilibrium state.

\subsection{Error analysis of the new ORC efficiency model}

With the reference of Eqs.(18) and (20), the error in the new ORC efficiency model is mainly caused by the assumptions of $\left.\left.v_{s}\right|_{p} \approx v\right|_{p}, T_{E C S T} \approx T_{1}$ and $q_{i} \approx q_{i, i d}$.

\subsubsection{Error contributed by the approximation of $a$-value}

The derivative of $\eta_{t}$ with respect to $a$ is 


$$
\frac{d \eta_{t}}{d a} \approx\left(1-\frac{T_{E C S T}}{T_{E H S T}}\right) \cdot \frac{\varepsilon_{e} \cdot \varepsilon_{g}-1 / \varepsilon_{p}}{(1-a)^{2}}
$$

Therefore,

$$
\frac{\Delta \eta_{t}}{\eta_{t}} \approx \frac{\varepsilon_{e} \cdot \varepsilon_{g} \cdot \varepsilon_{p}-1}{\left(\varepsilon_{e} \cdot \varepsilon_{g} \cdot \varepsilon_{p}-a\right)(1-a)} \Delta a
$$

With $10 \%$ relative error in $a$, the relative error in $\eta_{t}$ is about

$$
\frac{\Delta \eta_{t}}{\eta_{t}} \approx \frac{\varepsilon_{e} \cdot \varepsilon_{g} \cdot \varepsilon_{p}-1}{\left(\varepsilon_{e} \cdot \varepsilon_{g} \cdot \varepsilon_{p}-a\right)(1-a)} \cdot a \cdot 10 \%
$$

For most fluids in subcritical ORC, $a$ is less than 0.1 . With $\varepsilon_{e}, \varepsilon_{g}, \varepsilon_{p}$ of about $75 \%, 85 \%$ and $65 \%, \Delta \eta_{t} / \eta_{t}$ is expected to be less than $2 \%$.

Notably, if Eq.(24) is used to approximate the ORC efficiency in the conventional model expressed by Eq.(12), the relative error in $\eta_{t}$ will be much larger as follows.

$$
\begin{gathered}
\frac{d \eta_{t}}{d w_{e, i d}}=\frac{\varepsilon_{e} \cdot \varepsilon_{g}}{q_{i}} \\
\frac{\Delta \eta_{t}}{\eta_{t}} \approx \frac{\varepsilon_{e} \cdot \varepsilon_{g}}{w_{e, i d} \cdot \varepsilon_{e} \cdot \varepsilon_{g}-w_{p, i d} / \varepsilon_{p}} \Delta w_{e, i d}
\end{gathered}
$$

The error in $a$-value is expected to be similar with that in $w_{e, i d}$ according to Eq.(17). With $10 \%$ relative error in $w_{e, i d}$, the relative error in $\eta_{t}$ is about

$$
\frac{\Delta \eta_{t}}{\eta_{t}} \approx \frac{\varepsilon_{e} \cdot \varepsilon_{g}}{\varepsilon_{e} \cdot \varepsilon_{g}-\frac{w_{p, i d}}{w_{e, i d}} \cdot \frac{1}{\varepsilon_{p}}} 10 \% \approx 13 \%
$$

It is evident that, in light of the approximation of $w_{e, i d}$, the ORC efficiency modelled by Eq.(32) is more accurate than that modelled by Eq.(12) due to the error transfer from $w_{e, i d}$ 
to $a$. In other words, the effect of mis-estimation of $w_{e, i d}$ on the ORC efficiency calculated by the conventional model is much more significant than that on the efficiency obtained by the new model.

One reason is that $w_{e, i d}$ does not act as an independent variable. It can be determined by Eq.(13). There are different forms of $\eta_{t, i d}$ as expressed by Eqs.(3) and (16), in which the partial derivative of $\eta_{t, i d}$ with respect to $w_{e, i d}$ varies. The derivative is zero for Eq.(3) while it is positive in terms of Eq.(16). Analogically, the partial derivative of $\eta_{t}$ with respect to $w_{e, i d}$ is different when the form changes from Eq.(12) to Eq.(20).

\subsubsection{Error contributed by the approximation of $T_{E C S T}$}

For $T_{E C S T} \approx T_{1}$, error exists since most fluids leave the expander at superheated state. The derivative of $\eta_{t}$ with respect to $T_{E C S T}$ is

$$
\frac{d \eta_{t}}{d T_{E C S T}} \approx-\frac{1}{T_{E H S T}} \cdot \frac{\varepsilon_{e} \cdot \varepsilon_{g}-1 / \varepsilon_{p}}{1-a}
$$

Therefore,

$$
\frac{\Delta \eta_{t}}{\eta_{t}} \approx-\frac{\Delta T_{E C S T}}{T_{E H S T}-T_{E C S T}}
$$

For commercial ORC systems, the temperature difference between the hot and cold sides is generally larger than $80{ }^{\circ} \mathrm{C}$. Because the latent heat is prominent in the cooling process for most ORC fluids, $T_{E C S T}-T_{1}$ shall be small. Fig.2 shows the variation of $T_{E C S T}$ with the degree of superheat $\left(T_{4 s}-T_{1}\right)$ at the expander outlet on the condition of $T_{1}=30^{\circ} \mathrm{C} . T_{E C S T}-T_{1}$ is less than $1^{\circ} \mathrm{C}$ even when the degree of superheat reaches $20^{\circ} \mathrm{C}$. With an error in $\left|\Delta T_{E C S T}\right|$ of $1{ }^{\circ} \mathrm{C}, \Delta \eta_{t} / \eta_{t}$ is expected to be less than $1.25 \%$. More information on $T_{E C S T}-T_{1}$ is 
provided in Table 2. The condensation temperature is $30{ }^{\circ} \mathrm{C}$ and the evaporation temperature ranges from $100{ }^{\circ} \mathrm{C}$ to $150{ }^{\circ} \mathrm{C}$. Ideal ORC process is assumed. $T_{E C S T}-T_{1}$ is up to $3.29{ }^{\circ} \mathrm{C}$ with $\Delta \eta_{t} / \eta_{t}$ of about $4.06 \%$.

\subsubsection{Error counteraction by the approximation of $\boldsymbol{a}$-value and $T_{E C S T}$}

The new ORC model is developed by an error counteraction method. On one hand, the approximation of $T_{E C S T} \approx T_{1}$ will result in a lower cold side temperature and thus a higher

ORC efficiency than the real. On the other hand, the approximation of $\left.\left.v_{s}\right|_{p} \approx v\right|_{p}$ will lead to a higher $a$-value and thus a lower ORC efficiency. The new ORC efficiency model will benefit from the two competitive effects.

The overall error in regard to the approximation of $a$-value and $T_{E C S T}$ is expressed by

$$
\begin{aligned}
\left(\frac{\Delta \eta_{t}}{\eta_{t}}\right)_{o v e r} & \approx\left(\frac{\Delta \eta_{t}}{\eta_{t}}\right)_{E C S T}+\left(\frac{\Delta \eta_{t}}{\eta_{t}}\right)_{a} \\
& \approx-\frac{1}{T_{E H S T}-T_{E C S T}} \Delta T_{E C S T}+\frac{\varepsilon_{e} \cdot \varepsilon_{g} \cdot \varepsilon_{p}-1}{\left(\varepsilon_{e} \cdot \varepsilon_{g} \cdot \varepsilon_{p}-a\right)(1-a)} \Delta a
\end{aligned}
$$

Because

$$
\begin{gathered}
\Delta T_{E C S T}<0 \\
\Delta a>0 \\
T_{E C S T}<T_{E H S T} \\
a<\varepsilon_{e} \cdot \varepsilon_{g} \cdot \varepsilon_{p}<1 \\
\left(\frac{\Delta \eta_{t}}{\eta_{t}}\right)_{a}<0 \\
\left(\frac{\Delta \eta_{t}}{\eta_{t}}\right)_{E C S T}>0
\end{gathered}
$$


Therefore, the absolute error shall fulfill

$$
\left|\left(\frac{\Delta \eta_{t}}{\eta_{t}}\right)_{o v e r}\right|<\max \left\{\left|\left(\frac{\Delta \eta_{t}}{\eta_{t}}\right)_{E C S T}\right|,\left|\left(\frac{\Delta \eta_{t}}{\eta_{t}}\right)_{a}\right|\right\}
$$

For isentropic fluids, expansion proceeds on the saturation vapor curve, and the errors in $a$-value and $T_{E C S T}$ will be negligible. For dry fluids, a higher degree of superheat after expansion leads to larger difference between $T_{E C S T}$ and $T_{1}$. Meanwhile, the deviation of

$\left.v_{s}\right|_{p}$ from $\left.v\right|_{p}$ gets more significant. The error in ORC efficiency with $T_{E C S T} \approx T_{1}$ can be compensated by $\left.\left.v_{s}\right|_{p} \approx v\right|_{p}$.

\subsubsection{Error contributed by the approximation of $q_{i}$}

Due to the irreversible pumping process, $q_{i}$ is not equal to $q_{i, i d}$. The error in approximating $q_{i}$ is expressed by

$$
\mu\left(q_{i}\right)=\frac{q_{i, i d}-q_{i}}{q_{i}}
$$

Because $q_{i, i d}$ is always higher than $q_{i}$, the assumption of $q_{i, i d} \approx q_{i}$ will make the estimated efficiency lower than the true value according to Eq.(19). And the relative error in efficiency should be the opposite number of $\mu\left(q_{i}\right)$. Table 3 lists $\mu\left(q_{i}\right)$ on different working conditions. The pump efficiency is assigned to be 50\%. The condensation temperature is $30^{\circ} \mathrm{C}$. The maximum $\mu\left(q_{i}\right)$ is $1.78 \%$. In most cases, it is below $1 \%$. Lower $\mu\left(q_{i}\right)$ will be accompanied with more efficient pump. Meanwhile, fluid of greater cycle pressure range in the given temperature interval contributes to a higher pumping power demand [42], and a higher $\mu\left(q_{i}\right)$ generally eventuates. 


\subsubsection{Deviation of the estimated ORC efficiency}

Above all, high accuracy can be expected for the new model and only thermodynamic parameters at liquid-vapor equilibrium state are involved. For a comparison, the deviation of the ORC efficiency modelled by Eq.(32) from that calculated by REFPROP 9.0 using Eq.(12) is defined as

$$
\mu\left(\eta_{t}\right)=\frac{\eta_{t, E H S T}-\eta_{t, R E F P}}{\eta_{t, R E F P}}
$$

\section{Results and discussion}

Some assumptions are made while carrying out the simulation: (1) Evaporation and condensation processes are isobaric. (2) Expansion and compression processes are adiabatic. (3) Basic ORC consisting of expander, pump, evaporator and condenser is exemplified.

\subsection{Influence of the equivalent hot side temperature on the ORC efficiency under different conditions}

In this section influence of $\mathrm{T}_{\mathrm{EHST}}$ of the working fluids on the ORC cycle efficiency is evaluated on different operating conditions of evaporation and condensation temperatures, and expander and pump efficiencies. Fig. 3 shows variation of the ORC efficiency with TEHST at evaporation temperatures of $100^{\circ} \mathrm{C}, 120^{\circ} \mathrm{C}$ and $150^{\circ} \mathrm{C}$, respectively. To avoid crowd in the figure, seventeen working fluids are involved. The condensation temperature is $30^{\circ} \mathrm{C}$. The expander, pump and generator efficiencies are $75 \%, 65 \%$ and $85 \%$. The ORC efficiency is calculated by Eq. (12) and the thermodynamic parameters are based on REFPROP 9.0. Since this study is focused on subcritical cycle, some of the fluids whose critical temperatures are lower than the evaporation temperature are not selected at $120^{\circ} \mathrm{C}$ and $150^{\circ} \mathrm{C}$. Given the evaporation and condensation temperature, there is one-to-one 
correspondence between $\mathrm{T}_{\mathrm{EHST}}$ and the working fluid. ORC efficiency is found to be a strong function of $\mathrm{T}_{\mathrm{EHST}}$. It increases almost linearly with the increment in $\mathrm{T}_{\mathrm{EHST}}$, which is consistent with the Carnot theory.

Fluids of higher value of $\mathrm{T}_{\text {EHST }}$ show larger increment in ORC efficiency as compared to fluids of lower $\mathrm{T}_{\mathrm{EHST}}$ when the evaporation temperature increases. Therefore, ORC efficiency difference between any two fluids increases. For example, at evaporation temperature of $100^{\circ} \mathrm{C}$, relative increment in ORC efficiency of benzene over butane is $14.36 \%$ while it is $31.82 \%$ at evaporation temperature of $150{ }^{\circ} \mathrm{C}$.

Notably, though the variations of ORC efficiency with $\mathrm{T}_{\mathrm{EHST}}$ are similar for different evaporation temperatures, the sequences of working fluids are different. For example, cisbutene has higher cycle efficiency than tranbutene at $100^{\circ} \mathrm{C}$, but when the evaporation temperature is $150{ }^{\circ} \mathrm{C}$, the opposite is true. The reason is that the efficiency varies in a distinguishable way for each fluid. Some fluids have shown minor increment or even decrement in the ORC efficiency when the evaporation temperature increases, as depicted by the dashed lines in Fig.3. When increasing evaporation temperature from $120^{\circ} \mathrm{C}$ to $150^{\circ} \mathrm{C}$, ORC efficiencies of cisbutene and transbutene increase merely by $0.004 \%$ and $0.93 \%$, respectively. Thanks to $\mathrm{T}_{\mathrm{EHST}}$, the efficiency characteristic of each fluid can be explored. Fig. 4 shows the variation of the $\mathrm{T}_{\mathrm{EHST}}$ with the evaporation temperature. R236fa, isobutane, R245fa are taken as examples. $\mathrm{T}_{\mathrm{EHST}}$ increases with the increment in the evaporation temperature, but not in a monotone way. It decreases when evaporation temperature moves close to the fluid critical temperature. The decrement of $\mathrm{T}_{\mathrm{EHST}}$ is caused by the significant drop of latent heat $(H)$ as the evaporation temperature $\left(\mathrm{T}_{3}\right)$ increases, which can be expressed by the derivative of the function $H=\mathrm{f}\left(\mathrm{T}_{3}\right)$. At $100{ }^{\circ} \mathrm{C}, \mathrm{dH} / \mathrm{dT}_{3}$ is 
about $-1.46,-2.4$ and $-1.0 \mathrm{~kJ} /{ }^{\circ} \mathrm{C}$ for $\mathrm{R} 236 \mathrm{fa}$, isobutane and $\mathrm{R} 245 \mathrm{fa}$. It becomes $-7.4 \mathrm{~kJ} / \mathrm{K}$ for R236fa at $123{ }^{\circ} \mathrm{C},-18.3 \mathrm{~kJ} /{ }^{\circ} \mathrm{C}$ for isobutene at $133^{\circ} \mathrm{C}$ and $-25.8 \mathrm{~kJ} /{ }^{\circ} \mathrm{C}$ for $\mathrm{R} 245 \mathrm{fa}$ at $153^{\circ} \mathrm{C}$.

Effect of $\mathrm{T}_{\mathrm{EHST}}$ of the working fluids on the ORC efficiency at expander efficiency of $65 \%$ and $85 \%$ is shown in Fig.5. The evaporation temperature and condensation temperature are $100{ }^{\circ} \mathrm{C}$ and $30{ }^{\circ} \mathrm{C}$. The pump efficiency is $65 \%$. TEHST is independent on the expander efficiency. However, the ORC efficiency decreases with the decrement in the expander efficiency. The efficiency curves are almost parallel. When the expander efficiency increases from $65 \%$ to $85 \%$, the minimum increment in ORC efficiency is $2.43 \%$ with R227ea, while the maximum is $2.83 \%$ with benzene. Though the expander efficiency differs, the ORC efficiency variations with $\mathrm{T}_{\mathrm{EHST}}$ are similar.

Effect of $\mathrm{T}_{\mathrm{EHST}}$ of the working fluids on the ORC efficiency at pump efficiency of 50\% and $80 \%$ is shown in Fig.6. The expander efficiency is $75 \%$. The ORC efficiency is still an increasing function of $\mathrm{T}_{\mathrm{EHST}}$ at different pump efficiencies, and it decreases with the decrement in pump efficiency. However, the efficiency curves are not parallel, and the influence of pump efficiency on the cycle efficiency varies with the working fluid. When the pump efficiency drops from $80 \%$ to $50 \%$, the maximum decrement in ORC efficiency is $0.91 \%$ with R227ea, while the minimum is $0.025 \%$ with benzene. Fluid of lower critical temperature usually collocates with greater cycle pressure range. For example, the saturation pressure of benzene, R113, R245ca, R245fa, R236ea and RC318 at $100{ }^{\circ} \mathrm{C}$ is $0.18,0.43,0.92,1.26,1.57$ and $2.05 \mathrm{MPa}$, respectively. Attributed to greater operation pressure, the fluid's pumping power plays a more noticeable role in the cycle efficiency 
[42]. As a result, fluid of lower critical temperature is likely to suffer more from the degradation in pump performance.

Effect of $\mathrm{T}_{\mathrm{EHST}}$ of the working fluids on the ORC efficiency at condensation temperature of $20^{\circ} \mathrm{C}$ and $40^{\circ} \mathrm{C}$ is shown in Fig.7. The evaporation temperature, expander and pump efficiency are the same as the fixed ones in Figs.5 and 6. TEHST of each fluid changes with the condensation temperature. Even so, the ORC efficiency increases with increasing $\mathrm{T}_{\mathrm{EHST}}$.

Above all, in the wide range of the expander and pump efficiencies, evaporation and condensation temperature, the ORC efficiency is generally linearly proportional to $\mathrm{T}_{\mathrm{EHST}}$. The ORC efficiency is a very strong function of $\mathrm{T}_{\mathrm{EHST}}$. The qualitative relationship underscores the potential of $\mathrm{T}_{\mathrm{EHST}}$ as an indicator of ORC efficiency.

\subsection{Comparison among the equivalent hot side temperature and boiling point temperature, critical temperature, Jacobs number and Figure of Merit}

In order to clarify the advantages of $\mathrm{T}_{\mathrm{EHST}}$, comparison among $\mathrm{T}_{\mathrm{EHST}}$ and other indicators is made. The indicators include boiling point temperature $\left(T_{b p}\right)$, critical temperature $\left(T_{c}\right)$, Jacobs number (Ja) and FOM. The results are shown in Figs.8-11. In each of the figures, the ORC efficiency of a given fluid is constant. The evaporation temperature and condensation temperature are $100^{\circ} \mathrm{C}$ and $30^{\circ} \mathrm{C}$. The expander and pump efficiencies are $75 \%$ and $65 \%$. The symbols in red color denote $\mathrm{T}_{\mathrm{EHST}}$, while those in green color denote the existing indicators. The variation of ORC efficiency with $\mathrm{T}_{\mathrm{EHST}}$ is much more regular than those with $\mathrm{T}_{\mathrm{bp}}, \mathrm{T}_{\mathrm{c}}$ and Ja. The efficiency is in good relationship with FOM at $100^{\circ} \mathrm{C}$. However, the variation becomes less regular when the evaporation temperature increases to $150^{\circ} \mathrm{C}$ as shown in Fig. 12. The results show on the same boundary conditions, the ORC 
efficiency is directly proportional to $\mathrm{T}_{\text {EHST }}$ of the working fluids. The relationship between ORC efficiency and $\mathrm{T}_{\mathrm{EHST}}$ is solid.

The reason why $\mathrm{T}_{\mathrm{EHST}}$ is able to indicate the ORC efficiency monotonely may be that the cycle is subcritical. In this case, dry fluids are preferable to avoid superheat. The latent heat of condensation is usually dominant in the cooling process. The equivalent cold side temperature $\left(\mathrm{T}_{\mathrm{ECST}}\right)$ is very close to the condensation temperature in spite of the irreversibility in the expander. $\mathrm{T}_{\mathrm{ECST}}$ is roughly constant as the working fluid changes and TEHST turns out to be the main variable.

\subsection{Quantitative relationship between $\mathrm{ORC}$ efficiency and the equivalent hot side temperature}

The above section has presented the qualitative relationship between ORC efficiency and

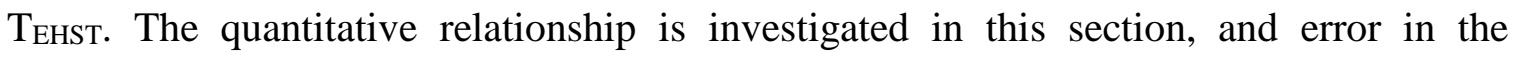
efficiency is explicated.

The molecular weight, critical temperature, critical pressure and coefficients in Antoine Equation of the working fluids are listed in Table 4. For R245ca, R227ea and R1234ze, Wagner Equation is used. The coefficients are $\mathrm{A}_{1}=-7.340, \mathrm{~A}_{2}=0.376, \mathrm{~A}_{3}=-0.148, \mathrm{~A}_{4}=-$ $12.361(\mathrm{R} 245 \mathrm{ca}), \mathrm{A}_{1}=-7.715, \mathrm{~A}_{2}=1.682, \mathrm{~A}_{3}=-2.674, \mathrm{~A}_{4}=-4.626(\mathrm{R} 227 \mathrm{ea})$ and $\mathrm{A}_{1}=-7.5046$, $\mathrm{A}_{2}=1.5524, \mathrm{~A}_{3}=-2.2353, \mathrm{~A}_{4}=-4.1018(\mathrm{R} 1234 \mathrm{ze})$. For R124, $\mathrm{A}_{1}=-7.76544, \mathrm{~A}_{2}=2.36923$, $\mathrm{A}_{3}=-9.33775, \mathrm{~A}_{4}=217.292$ with $\ln p / p_{c}=T_{c} / T \cdot\left(A_{1} \tau+A_{2} \tau^{1.5}+A_{3} \tau^{3}+A_{4} \tau^{6}\right)$. For R236ea, modified Riedel Equation is employed and the coefficients are $A^{\prime}=15.9302, B^{\prime}=-1725.4045$, $\mathrm{C}^{\prime}=-0.4984, \mathrm{D}^{\prime}=3.2139 \times 10^{-6}$, and $\mathrm{E}^{\prime}=-2.0096 \times 10^{5}$.

The estimated $a$-value and ORC efficiency are presented in Tables 5 and 6 . The condensation temperature of $30{ }^{\circ} \mathrm{C}$, expander efficiency of $75 \%$, pump efficiency of $65 \%$ 
and generator efficiency of $85 \%$ are assumed. In general, fluid of a higher critical temperature offers a lower $a$-value. This may be attributed to a higher ratio of the specific saturation vapor and liquid volumes $\left(v_{V} / v_{L}\right)$. For example, at $100{ }^{\circ} \mathrm{C}, v_{V} / v_{L}$ is about 165.7, 88.2, 26.5, 15.5, 7.5 and 1.2 for benzene, acetone, R123, R245fa, isobutane and R227ea, respectively. Given the fluid, $a$-value increases with the increment in the evaporation temperature, which is very significant as the critical temperature is approached. The maximum $a$-value is $9.07 \%$ with R227ea at the evaporation temperature of $100{ }^{\circ} \mathrm{C}$. Benzene has the highest ORC efficiency at given evaporation temperature. The relative deviation $\mu\left(\eta_{t}\right)$ of the estimated efficiency from that modelled in the conventional way with REFPROP database is also exhibited in Table 6. Because only one digit after decimal point is reserved, $\mu\left(\eta_{t}\right)$ is expressed as zero for some fluids. Both negative and positive values of $\mu\left(\eta_{t}\right)$ exist. As mentioned in Section 3.4, $a$-value by the model developed in this work and the approximation of $q_{i}$ will result in an underestimated ORC efficiency, while the approximation of $\mathrm{T}_{\mathrm{ECST}}$ will lead to an overestimated one. Negative $\mu\left(\eta_{t}\right)$ is usually due to dominant effect by $a$-value and $q_{i}=q_{i, i d}$, which seems valid for slightly dry and isentropic fluids such as transbutene, isobutene, isobutane and cisbutene. Positive $\mu\left(\eta_{t}\right)$ is accompanied with dry fluids such as cyclohexane, R113 and isopentane, for which $\mathrm{T}_{\mathrm{ECST}}$ is higher than the condensation temperature $\left(T_{1}\right)$ owing to the superheated exhaust from the expander.

In most cases, $\mu\left(\eta_{t}\right)$ is within $\pm 2 \%$. R245fa is a hydro-fluorocarbon (HFC) with zero Ozone Depletion Potential (ODP). Nowadays, it is a common working fluid in commercial ORC installations such as GE CleanCycle ${ }^{\mathrm{TM}}$ [43] and Verdicorp ORC model [44]. The estimated ORC efficiency using this fluid shows high accuracy, and the relative bias is 
from $-0.3 \%$ to $0.5 \%$. Among the fluids, the deviation of the estimated efficiency is largest in the presence of isopentane. It is a highly dry working fluid. For example, given the expander efficiency of 0.75 and evaporation and condensation temperature of $150^{\circ} \mathrm{C}$ and $30{ }^{\circ} \mathrm{C}$, the fluid leaving the expander will be at $87^{\circ} \mathrm{C}$ with a degree of superheat of $57^{\circ} \mathrm{C}$. The high degree of superheat causes relatively appreciable error in approximating $\mathrm{T}_{\mathrm{ECST}}$.

Aside from the basic thermodynamic processes represented in Fig.1, another type of ORC with a degree of superheat $\left(\Delta T_{\text {super }}\right)$ at the expander inlet is taken into consideration for a comprehensive evaluation of the new model. In the superheat cycle, state points 1, 2, $2 \mathrm{~s}$ and $4^{\prime}$ do not change, while state point 3 moves upward by $5^{\circ} \mathrm{C}$ along the isobaric curve. State points 4 and $4 \mathrm{~s}$ change consequently. Table 7 lists $\mathrm{T}_{\mathrm{EHST}}$ of the working fluids in the evaporation temperature range from $100{ }^{\circ} \mathrm{C}$ to $150^{\circ} \mathrm{C}$. The estimated ORC efficiency and relative error are provided in Table 8 under the similar assumption made in Table 6 . Resulting from $5{ }^{\circ} \mathrm{C}$ of $\Delta T_{\text {super }}$, TEHST goes up when the evaporation temperature and working fluid are allocated in comparison with that in Table 6 . The increment becomes more noticeable at higher evaporation temperature and for fluids of lower critical temperature. Unlike $\mathrm{T}_{\mathrm{EHST}}$ and $\eta_{t, \text { EHST }}$, the estimated $a$-value is not affected by $\Delta T_{\text {super }}$ because of unvaried integration path and pressure at a given evaporation temperature.

$\mu\left(\eta_{t}\right)$ in Table 8 is within an interval of $(-1.4 \%,+4.6 \%)$. The developed ORC efficiency model seems to have a lower accuracy in the superheat ORC. There can be two reasons. The first one is that for many dry fluids, a degree of superheat at the expander inlet does not elevate the ORC efficiency [45]. In fact, the ORC efficiency of isopentane decreases from $12.43 \%$ to $12.41 \%$ as $\Delta T_{\text {super }}$ climbs from $0{ }^{\circ} \mathrm{C}$ to $5{ }^{\circ} \mathrm{C}$. On the contrary, $\mathrm{T}_{\mathrm{EHST}}$ is increased by $\Delta T_{\text {super }}$ and this leads to a higher efficiency based on the proposed model. The 
positive deviation of $\eta_{t, E H S T}$ from $\eta_{t, \text { REFP }}$ hence becomes larger. The second reason lies in the diverse error in $a$-value as $\Delta T_{\text {super }}$ changes. Take butene for example. At an evaporation temperature of $140^{\circ} \mathrm{C}$, the fluid after ideal expansion is at binary phase state with a quality of about 0.98 for a basic ORC. In this situation, $\mathrm{T}_{\mathrm{ECST}}$ is equal to the condensation temperature. And the error caused by the approximation of $q_{i}$ and $a$-value is primary. The error in $q_{i} \approx q_{i d}$ is in weak relation with $\Delta T_{\text {super }}$ regarding the constant pump efficiency, while the error in $a$-value varies significantly. With the increment in $\Delta T_{\text {super }}$ the difference of $\left.v\right|_{p}-\left.v_{s}\right|_{p}$ increases, and it is likely to co-occur with a lower estimated ORC efficiency as mentioned in Section 3.4.3. Therefore, the negative deviation of $\eta_{t, E H S T}$ for butene changes from $-0.7 \%$ without superheat to $-1.4 \%$ at $\Delta T_{\text {super }}$ of $5{ }^{\circ} \mathrm{C}$.

It needs to be emphasized that isentropic and dry fluids are favorable in the ORC, and superheat at the expander inlet should be avoided $[8,46]$. In the presence of superheat cycle, thermodynamic parameters of the working fluid at superheat state are also required, which will make the proposed model less convenient.

\section{Case study}

A newly developed refrigerant, Hydro-Fluoro-Olefin $\mathrm{HFO} 1336 \mathrm{mzzZ}$ (cis- $\mathrm{CF}_{3} \mathrm{CH}=\mathrm{CHCF}_{3}$ ) is exemplified. It is a dry fluid, and has no ODP and extremely good thermal stability at temperature up to $250^{\circ} \mathrm{C}$ [47]. Its GWP is only 9 , which is much lower than that of the widely used R245fa (about 1030). Some properties are listed in Table 9. HFO1336mzzZ exhibits attractive physical characteristics for use in low and medium temperature ORC applications. 
The exploration of thermodynamic performance of this new working fluid in the potential ORC application regarding the conventional efficiency model will require a detailed knowledge of its PVT behavior, but experimental data for this compound in literature are rare. So far studies on the performance of HFO1336mzzZ as an ORC working fluid have been based on data from DuPont, which may be incomplete and are not available in open literature [48]. Comprehensive information about this fluid is unavailable on the database of REFPROP and CoolProp. Though it is difficult to obtain the accurate thermodynamic parameters in the wide temperature and pressure ranges at gas state, the parameters at saturation liquid/vapor state are easier to determine. The experiment work on saturation parameters is less cumbersome. The saturation temperature-pressure and temperature-entropy $(T-s)$ graphs of HFO1336mzzZ are accessible $[49,50]$. Besides, the vapor-liquid equilibria of this fluid can be predicted by molecular simulations. For example, a transferable force field model has been applied for simulation studies on saturated vapor pressure, vapor density and liquid density and heats of vaporization of fluoropropenes, and the simulated data generally agree well with available experimental data [51].

The specific liquid enthalpy $\left(h_{l, s}\right)$, vapor enthalpy $\left(h_{v, s}\right)$, liquid entropy $\left(s_{l, s}\right)$, vapor entropy $\left(s_{v, s}\right)$, vapor volume $\left(v_{v, s}\right)$ and pressure $\left(p_{s}\right)$ of HFO1336mzzZ at the saturation state are listed in Table 10 . The saturation liquid density at $30^{\circ} \mathrm{C}$ is $1352 \mathrm{~kg} / \mathrm{m}^{3}$, which is useful for the ascertainment of pump power. With the thermodynamic parameters at liquidvapor equilibrium state, the ORC efficiency can be calculated by the new model built in this work. Some results are listed in Table 11. R245fa is referenced. The efficiencies of the expander and generator are $75 \%$ and $85 \%$. The condensation temperature is $30{ }^{\circ} \mathrm{C}$. Basic ORC without superheat at the expander inlet is under discussion. Compared with 
R245fa, HFO1336mmZ has a lower $a$-value. For an inefficient pumping process, the exergy loss in case of HFO1336mmZ will be less appreciable than that with R245fa. On the other hand, $\mathrm{T}_{\mathrm{EHST}}$ of HFO1336mmZ is lower in a wide range of ORC evaporation temperature, with the exception of $150{ }^{\circ} \mathrm{C}$ which is close to the critical temperature of R245fa. Due to the competitive effects of $a$-value and $\mathrm{T}_{\mathrm{EHST}}$, the ORC efficiencies of HFO1336mmZ and R245fa are comparable. Given a modest pump efficiency of $65 \%$, HFO1336mmZ has no efficiency superiority over R245fa unless the evaporation temperature exceeds $130{ }^{\circ} \mathrm{C}$. The superiority is more appreciable with less efficient pump and higher operating temperature.

\section{Conclusions}

$\mathrm{T}_{\mathrm{EHST}}$ is determined by the thermodynamic parameters at the liquid-vapor equilibrium state. Given the condensation temperature and working fluid, it is a function with respect to the evaporation temperature. This indicator is strongly related with the ORC efficiency. On the same operating conditions, fluid of higher $\mathrm{T}_{\text {EHST }}$ generally leads to more efficient heat-topower conversion. This rule is applicable in a wide range of hot and cold side temperatures, expander and pump efficiencies. It is concluded that $\mathrm{T}_{\mathrm{EHST}}$ provides a more universal guideline on the ORC efficiency assessment as compared to some existing indicators such as boiling point temperature, critical temperature, Jacobs number and Figure of Merit.

$\mathrm{T}_{\mathrm{EHST}}$ generally increases with the increment in the evaporation temperature for each fluid. Nevertheless, as the evaporation temperature approaches to critical temperature of the fluid, TEHST increases slowly and may even decrease. This explains why the cycle efficiencies of some fluids decrease when the evaporation temperature gets close to their critical temperatures. 
A new ORC efficiency model is built with the assistance of $\mathrm{T}_{\mathrm{EHST}}$. In contrast to the conventional model, the efficiency in the new model is determined by the liquid-vapor equilibrium data of the fluid and it is unnecessary to get information on parameters at superheat state. An error compensation method is developed by the approximation of $a$ value and $\mathrm{T}_{\mathrm{ECST}}$. On the use of twenty-seven fluids, the ORC efficiency obtained by the hypothetical model is in good agreement with the actual. The relative error is from $-0.7 \%$ to $3.4 \%$. The largest deviation occurs when the highly dry fluid (isopentane) is employed. For more than half of the investigated fluids, the relative error is within $\pm 0.6 \%$.

The accuracy of the proposed model becomes relatively lower in the situation of $5{ }^{\circ} \mathrm{C}$ of superheat at the expander inlet. The deviation of estimated efficiency from the real is enlarged due to the unwanted overheat and has a value up to $4.6 \%$.

A case study using the newly developed fluid of HFO-1336mzz-Z is conducted with expander and generator efficiency of $75 \%$ and $85 \%$. Though this fluid is promising in terms of the environmental issues, it has efficiency superiority over R245fa only at relatively high evaporation temperature $\left(>130^{\circ} \mathrm{C}\right)$ or relatively lower pump efficiency $(<65 \%)$.

\section{Acknowledgment}

This study was sponsored by the National Science Foundation of China (51476159, 51378483, 51206154), Project of EU Marie Curie International Incoming Fellowships (703746), Anhui Provincial Natural Science Foundation (1608085QE96), CAS-TWAS presidential fellowship program, and Dongguan Innovative Research Team Program (2014607101008).

\section{References}


1. Tchanche, B.F., et al., Low-grade heat conversion into power using organic Rankine cycles - A review of various applications. Renewable and Sustainable Energy Reviews, 2011. 15(8): p. 3963-3979.

2. Wang, J., et al., Thermodynamic analysis and optimization of an (organic Rankine cycle) ORC using low grade heat source. Energy, 2013. 49(0): p. 356-365.

3. Chen, H., D.Y. Goswami, and E.K. Stefanakos, A review of thermodynamic cycles and working fluids for the conversion of low-grade heat. Renewable and Sustainable Energy Reviews, 2010. 14(9): p. 3059-3067.

4. Quoilin, S., Sustainable Energy Conversion Through the Use of Organic Rankine Cycles for Waste Heat Recovery and Solar Applications. 2011, University of Liège (Belgium.

5. Maizza, V. and A. Maizza, Working fluids in non-steady flows for waste energy recovery systems. Applied Thermal Engineering, 1996. 16(7): p. 579-590.

6. Papadopoulos, A.I., M. Stijepovic, and P. Linke, On the systematic design and selection of optimal working fluids for Organic Rankine Cycles. Applied Thermal Engineering, 2010. 30(6): p. 760-769.

7. Wang, J., J. Zhang, and Z. Chen, Molecular entropy, thermal efficiency, and designing of working fluids for organic Rankine cycles. International Journal of Thermophysics, 2012. 33(6): p. 970-985.

8. Saleh, B., et al., Working fluids for low-temperature organic Rankine cycles. Energy, 2007. 32(7): p. 1210-1221.

9. Maizza, V. and A. Maizza, Unconventional working fluids in organic Rankinecycles for waste energy recovery systems. Applied thermal engineering, 2001. 21(3): p. 381-390.

10. Mikielewicz, D. and J. Mikielewicz, A thermodynamic criterion for selection of working fluid for subcritical and supercritical domestic micro CHP. Applied Thermal Engineering, 2010. 30(16): p. 2357-2362.

11. Kuo, C.-R., et al., Analysis of a 50kW organic Rankine cycle system. Energy, 2011. 36(10): p. 5877-5885.

12. Lai, N.A., M. Wendland, and J. Fischer, Working fluids for high-temperature organic Rankine cycles. Energy, 2011. 36(1): p. 199-211. 
13. Aljundi, I.H., Effect of dry hydrocarbons and critical point temperature on the efficiencies of organic Rankine cycle. Renewable Energy, 2011. 36(4): p. 11961202.

14. Heberle, F. and D. Brüggemann, Exergy based fluid selection for a geothermal Organic Rankine Cycle for combined heat and power generation. Applied Thermal Engineering, 2010. 30(11): p. 1326-1332.

15. Liu, B.-T., K.-H. Chien, and C.-C. Wang, Effect of working fluids on organic Rankine cycle for waste heat recovery. Energy, 2004. 29(8): p. 1207-1217.

16. He, C., et al., The optimal evaporation temperature and working fluids for subcritical organic Rankine cycle. Energy, 2012. 38(1): p. 136-143.

17. Desideri, A., et al., Experimental comparison of organic fluids for low temperature ORC (organic Rankine cycle) systems for waste heat recovery applications. Energy, 2016. 97: p. 460-469.

18. He, C., et al., A new selection principle of working fluids for subcritical organic Rankine cycle coupling with different heat sources. Energy, 2014. 68: p. 283-291.

19. Lecompte, S., et al., Part load based thermo-economic optimization of the Organic Rankine Cycle (ORC) applied to a combined heat and power (CHP) system. Applied Energy, 2013. 111: p. 871-881.

20. Cataldo, F., et al., Fluid selection of Organic Rankine Cycle for low-temperature waste heat recovery based on thermal optimization. Energy, 2014. 72: p. 159-167.

21. Song, J., et al., Thermodynamic analysis and performance optimization of an ORC (Organic Rankine Cycle) system for multi-strand waste heat sources in petroleum refining industry. Energy, 2014. 71: p. 673-680.

22. Zhai, H., L. Shi, and Q. An, Influence of working fluid properties on system performance and screen evaluation indicators for geothermal ORC (organic Rankine cycle) system. Energy, 2014. 74: p. 2-11.

23. Xue, X., et al., Thermodynamic analysis and optimization of a two-stage organic Rankine cycle for liquefied natural gas cryogenic exergy recovery. Energy, 2015. 83: p. 778-787.

24. Hajabdollahi, Z., et al., Thermo-economic environmental optimization of Organic Rankine Cycle for diesel waste heat recovery. Energy, 2013. 63: p. 142-151. 
25. Astolfi, M., et al., Binary ORC (organic Rankine cycles) power plants for the exploitation of medium-low temperature geothermal sources-Part A:

Thermodynamic optimization. Energy, 2014. 66: p. 423-434.

26. Astolfi, M., et al., Binary ORC (Organic Rankine Cycles) power plants for the exploitation of medium-low temperature geothermal sources-Part B: Technoeconomic optimization. Energy, 2014. 66: p. 435-446.

27. Yang, M.-H. and R.-H. Yeh, Economic performances optimization of an organic Rankine cycle system with lower global warming potential working fluids in geothermal application. Renewable Energy, 2016. 85: p. 1201-1213.

28. Borsukiewicz-Gozdur, A., Exergy analysis for maximizing power of organic Rankine cycle power plant driven by open type energy source. Energy, 2013. 62: p. $73-81$.

29. Wang, E., et al., Study of working fluid selection of organic Rankine cycle (ORC) for engine waste heat recovery. Energy, 2011. 36(5): p. 3406-3418.

30. Heberle, F., M. Preißinger, and D. Brüggemann, Zeotropic mixtures as working fluids in Organic Rankine Cycles for low-enthalpy geothermal resources. Renewable Energy, 2012. 37(1): p. 364-370.

31. Feng, Y., et al., Thermoeconomic comparison between pure and mixture working fluids of organic Rankine cycles (ORCs) for low temperature waste heat recovery. Energy Conversion and Management, 2015. 106: p. 859-872.

32. Maraver, D., et al., Systematic optimization of subcritical and transcritical organic Rankine cycles (ORCs) constrained by technical parameters in multiple applications. Applied energy, 2014. 117: p. 11-29.

33. Toffolo, A., et al., A multi-criteria approach for the optimal selection of working fluid and design parameters in Organic Rankine Cycle systems. Applied Energy, 2014. 121: p. 219-232.

34. Shu, G., et al., Alkanes as working fluids for high-temperature exhaust heat recovery of diesel engine using organic Rankine cycle. Applied Energy, 2014. 119: p. 204-217. 
35. Wang, J., et al., Multi-objective optimization of an organic Rankine cycle (ORC) for low grade waste heat recovery using evolutionary algorithm. Energy Conversion and Management, 2013. 71: p. 146-158.

36. Mago, P.J., et al., An examination of regenerative organic Rankine cycles using dry fluids. Applied Thermal Engineering, 2008. 28(8): p. 998-1007.

37. Srinivasan, K.K., P.J. Mago, and S.R. Krishnan, Analysis of exhaust waste heat recovery from a dual fuel low temperature combustion engine using an Organic Rankine Cycle. Energy, 2010. 35(6): p. 2387-2399.

38. Chen, Q., J. Xu, and H. Chen, A new design method for organic Rankine cycles with constraint of inlet and outlet heat carrier fluid temperatures coupling with the heat source. Applied Energy, 2012. 98: p. 562-573.

39. Hung, T., T. Shai, and S. Wang, A review of organic Rankine cycles (ORCs) for the recovery of low-grade waste heat. Energy, 1997. 22(7): p. 661-667.

40. Frenkel, D. and B. Smit, Understanding molecular simulation: from algorithms to applications. Vol. 1. 2001: Academic press.

41. Martin, M.G., MCCCS Towhee: a tool for Monte Carlo molecular simulation. Molecular Simulation, 2013. 39(14-15): p. 1212-1222.

42. Borsukiewicz-Gozdur, A., Pumping work in the organic Rankine cycle. Applied Thermal Engineering, 2013. 51(1): p. 781-786.

43. GE - Model Clean Cycle 125 $5^{\mathrm{TM}}$ - Organic Rankine Cycle (ORC) Systems. 2015.12.11]; Available from: http://www.environmental-expert.com/products/gemodel-clean-cycle-125-organic-rankine-cycle-orc-systems-177085.

44. Verdicorp's Organic Rankine Cycle System. . 2015.11.10]; Available from: http://verdicorp.com/orc.html.

45. Hung, T.-C., T. Shai, and S. Wang, A review of organic Rankine cycles (ORCs) for the recovery of low-grade waste heat. Energy, 1997. 22(7): p. 661-667.

46. Hung, T.-C., Waste heat recovery of organic Rankine cycle using dry fluids. Energy Conversion and Management, 2001. 42(5): p. 539-553.

47. Juhasz JR, Simoni LD. A review of potential working fluids for low temperature organic Rankine cycles in waste heat recovery. The third edition of the 
International Seminar on ORC Power Systems (ASME ORC 2015),Brussels, 12 to 14 October, 2015.

48. Raabe, G., Molecular Simulation Studies on the Vapor-Liquid Equilibria of the cis-and trans-HCFO-1233zd and the cis-and trans-HFO-1336mzz. Journal of Chemical \& Engineering Data, 2015. 60(8): p. 2412-2419.

49. Molés, F., et al., Low GWP alternatives to HFC-245fa in Organic Rankine Cycles for low temperature heat recovery: HCFO-1233zd-E and HFO-1336mzz-Z. Applied Thermal Engineering, 2014. 71(1): p. 204-212.

50. Kontomaris K. HFO-1336mzz-Z: High Temperature Chemical Stability and Use as A Working Fluid in Organic Rankine Cycles. International Refrigeration and Air Conditioning Conference, Purdue University, 2014.

51. Raabe, G., Molecular modeling of fluoropropene refrigerants. The Journal of Physical Chemistry B, 2012. 116(19): p. 5744-5751.

52. Eon, C., C. Pommier, and G. Guiochon, Vapor pressures and second virial coefficients of some five-membered heterocyclic derivatives. Journal of Chemical \& Engineering Data, 1971. 16(4): p. 408-410.

53. Kerns, W., R. Anthony, and P. Eubank. Volumetric properties of cyclohexane vapor. in AIChE Symp. Ser. 1974.

54. Ambrose, D., C. Sprake, and R. Townsend, Thermodynamic properties of organic oxygen compounds XXXIII. The vapour pressure of acetone. The Journal of Chemical Thermodynamics, 1974. 6(7): p. 693-700.

55. Goodwin, A., et al., The vapor pressure of 1, 1-dichloro-2, 2, 2-trifluoroethane (R123). International journal of thermophysics, 1992. 13(6): p. 999-1009.

56. Di Nicola, G. and G. Passerini, Saturated pressure and gas phase PVT data for 1, 1, 2, 2, 3-pentafluoropropane $(R-245 \mathrm{ca})$. Journal of Chemical \& Engineering Data, 2002. 47(4): p. 882-886.

57. Di Nicola, G., Vapor pressure and gas phase $P$-V-T data for $1,1,1,3,3$ pentafluoropropane (R-245fa). Journal of Chemical \& Engineering Data, 2001. 46(6): p. 1619-1622. 
58. Di Nicola, G. and G. Giuliani, Vapor Pressure and P-V-T Measurements for 1, 1, 1, 2, 3, 3-Hexafluoropropane (R-236ea). Journal of Chemical \& Engineering Data, 2000. 45(6): p. 1075-1079.

59. Das, T.R., C.O. Reed Jr, and P.T. Eubank, PVT [pressure-volume-temperature] surface and thermodynamic properties of isobutane. Journal of Chemical and Engineering Data, 1973. 18(3): p. 253-262.

60. Di Nicola, G., et al., Saturated Pressure and P-V-T Measurements for 1, 1, 1, 3, 3, 3-Hexafluoropropane (R-236fa). Journal of Chemical \& Engineering Data, 1999. 44(4): p. 696-700.

61. Di Nicola, G., PVT Behavior of 1, 1, 1, 2, 3, 3, 3-Heptafluoropropane (R227ea). Journal of Chemical \& Engineering Data, 2003. 48(5): p. 1332-1336. 


\section{Figure Legend}

Fig.1. T-s diagram of ORC

Fig.2. Variation of $\mathrm{T}_{\mathrm{ECST}}$ with the degree of superheat at the expander outlet

Fig.3. Influence of $\mathrm{T}_{\mathrm{EHST}}$ of the working fluids on the ORC efficiency at evaporation temperature of 100,120 and $150{ }^{\circ} \mathrm{C}$

Fig. 4. Variation of $\mathrm{T}_{\text {EHST }}$ of the working fluids with the evaporation temperature

Fig. 5. Influence of $\mathrm{T}_{\mathrm{EHST}}$ of the working fluids on the $\mathrm{ORC}$ efficiency at expander efficiency of $65 \%$ and $85 \%$

Fig. 6. Influence of $\mathrm{T}_{\mathrm{EHST}}$ of the working fluids on the ORC efficiency at pump efficiency of $50 \%$ and $80 \%$

Fig. 7. Influence of $\mathrm{T}_{\mathrm{EHST}}$ of the working fluids on the ORC efficiency at condensation temperature of $20^{\circ} \mathrm{C}$ and $40^{\circ} \mathrm{C}$

Fig. 8. Effect of $\mathrm{T}_{\mathrm{ESHT}}$ and boiling point temperature on the ORC efficiency of working fluids

Fig. 9. Effect of $\mathrm{T}_{\mathrm{ESHT}}$ and critical temperature on the ORC efficiency of working fluids

Fig. 10. Effect of $\mathrm{T}_{\text {ESHT }}$ and Jacobs number on the ORC efficiency of working fluids

Fig.11. Effect of $\mathrm{T}_{\mathrm{ESHT}}$ and Figure of Merit on the ORC efficiency of working fluids at evaporation and condensation temperature of $100^{\circ} \mathrm{C}$ and $30^{\circ} \mathrm{C}$ respectively

Fig. 12. Effect of TESHT and Figure of Merit on the ORC efficiency of working fluids at evaporation and condensation temperature of $150^{\circ} \mathrm{C}$ and $30^{\circ} \mathrm{C}$ respectively 


\section{Table Legend}

Table $1 . \mathrm{T}_{\mathrm{EHST}}$ of the working fluids in the evaporation temperature range from $100{ }^{\circ} \mathrm{C}$ to $150^{\circ} \mathrm{C}$, unit: ${ }^{\circ} \mathrm{C}$

Table 2. Error caused by approximating the equivalent cold side temperature, unit: ${ }^{\circ} \mathrm{C}$

Table 3. Relative error in approximating the heat input, unit: $\%$

Table 4. Some properties of the working fluids

Table 5. Estimated $a$-value of the working fluids in the evaporation temperature range from $100^{\circ} \mathrm{C}$ to $150^{\circ} \mathrm{C}$, unit: $\%$

Table 6. Estimated efficiency of the working fluids unit: \%

Table 7. TEHST of the working fluids with a degree of superheat of $5^{\circ} \mathrm{C}$ at the expander inlet, unit: ${ }^{\circ} \mathrm{C}$

Table 8. Estimated efficiency of the working fluids with a degree of superheat of $5{ }^{\circ} \mathrm{C}$ at the expander inlet, unit: $\%$

Table 9. Some properties of HFO1336mzzZ

Table 10. Thermodynamic parameters of HFO1336mzzZ at saturation state

Table 11. Estimated efficiency of HFO1336mmZ compared with R245fa 


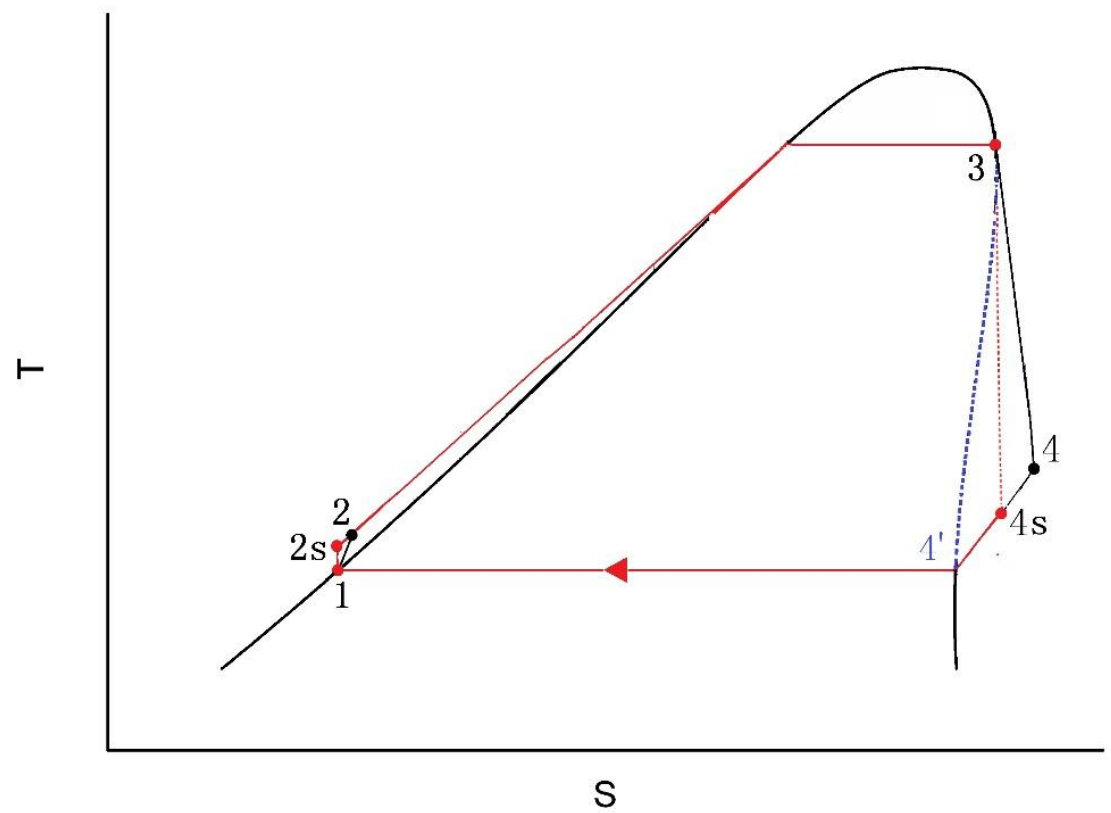

Fig.1. $T$-s diagram of ORC

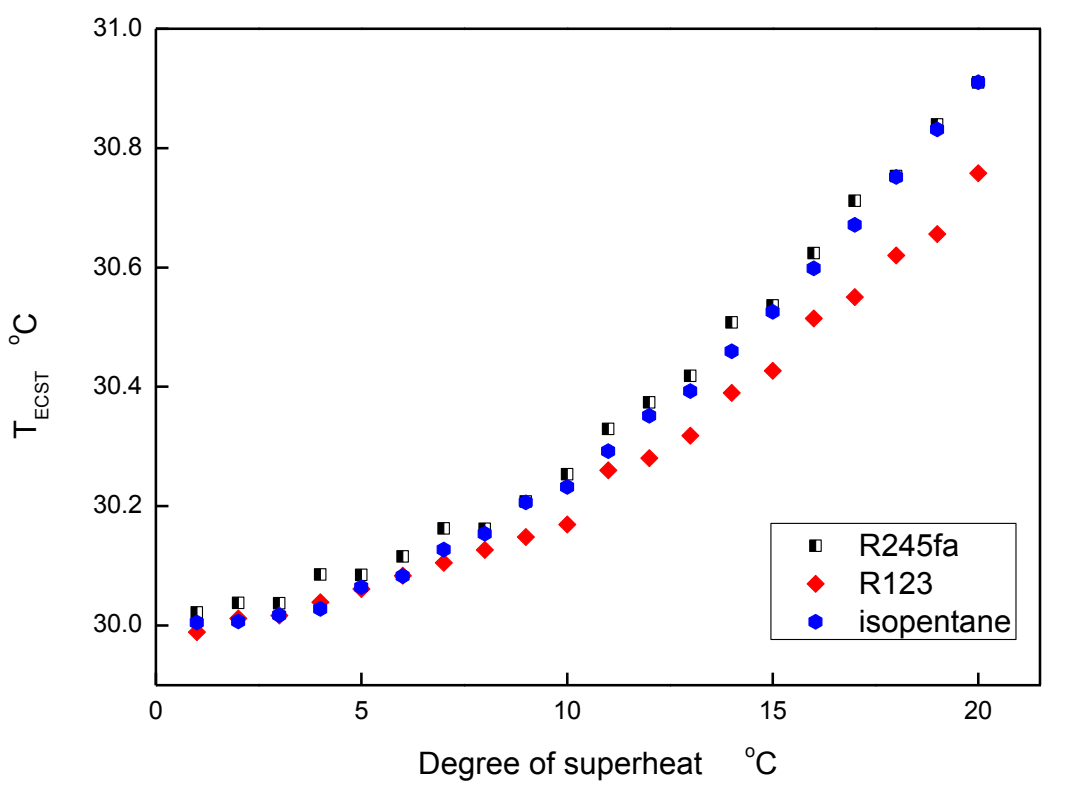

Fig.2. Variation of $\mathrm{T}_{\mathrm{ECST}}$ with the degree of superheat at the expander outlet 


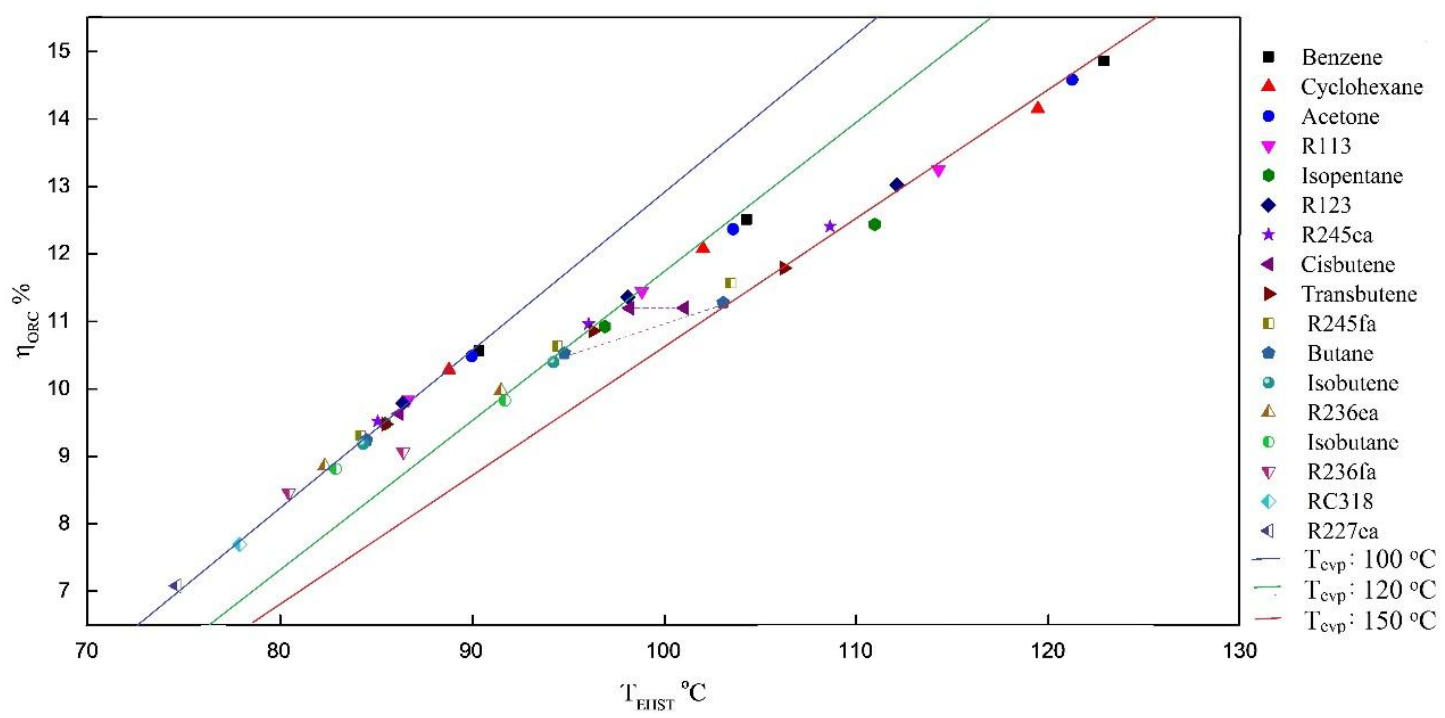

Fig.3. Influence of $\mathrm{T}_{\mathrm{EHST}}$ of the working fluids on the ORC efficiency at evaporation temperature of 100,120 and $150{ }^{\circ} \mathrm{C}$

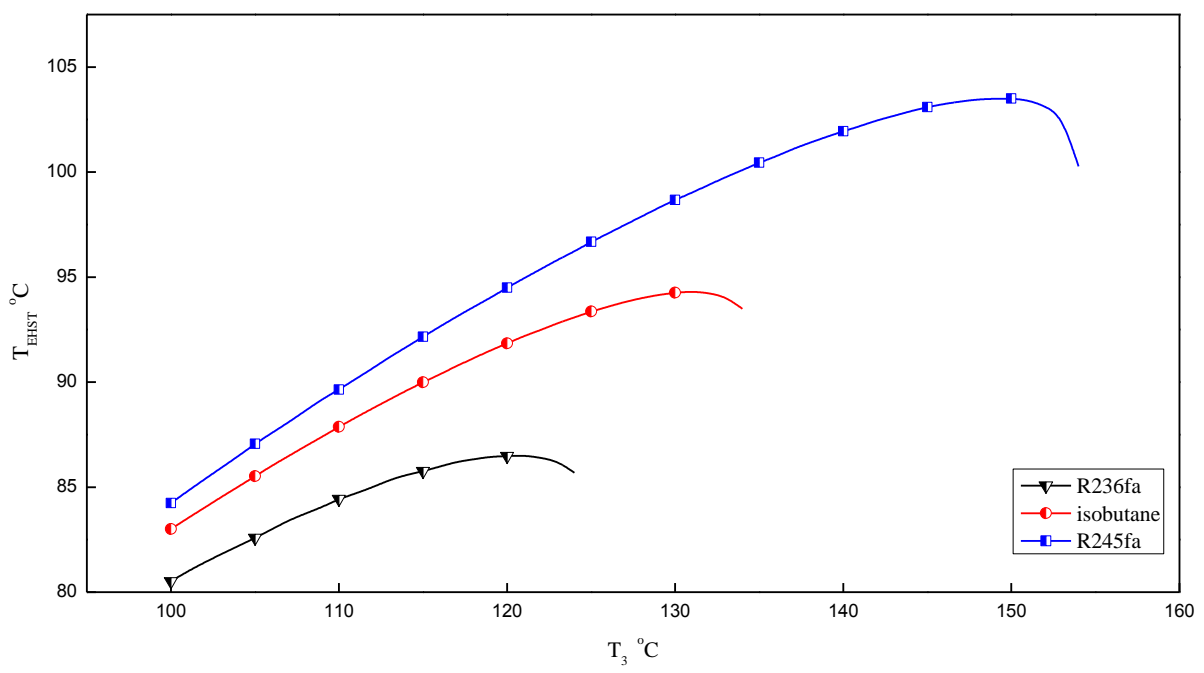

Fig. 4. Variation of $\mathrm{T}_{\mathrm{EHST}}$ of the working fluids with the evaporation temperature 


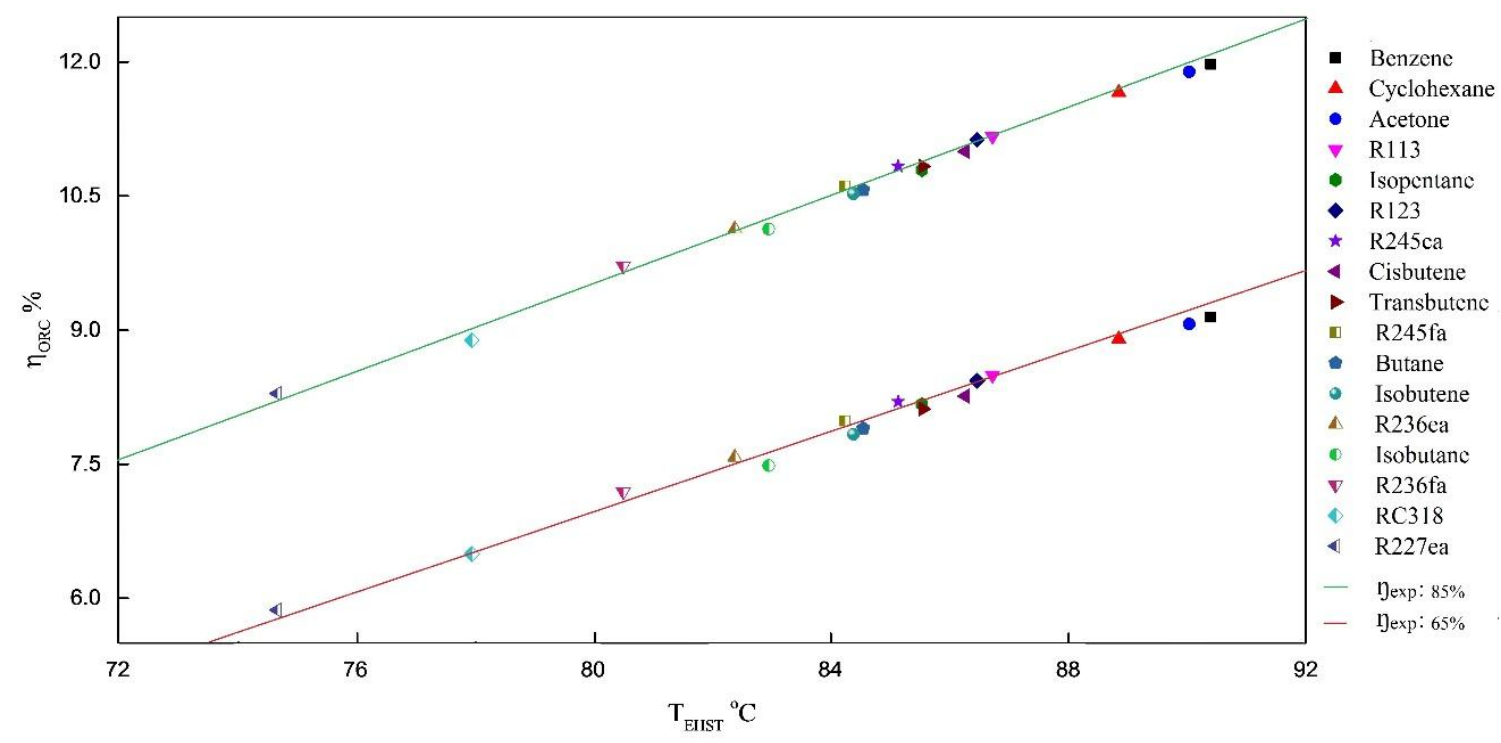

Fig. 5. Influence of $\mathrm{T}_{\mathrm{EHST}}$ of the working fluids on the ORC efficiency at expander efficiency of $65 \%$ and $85 \%$

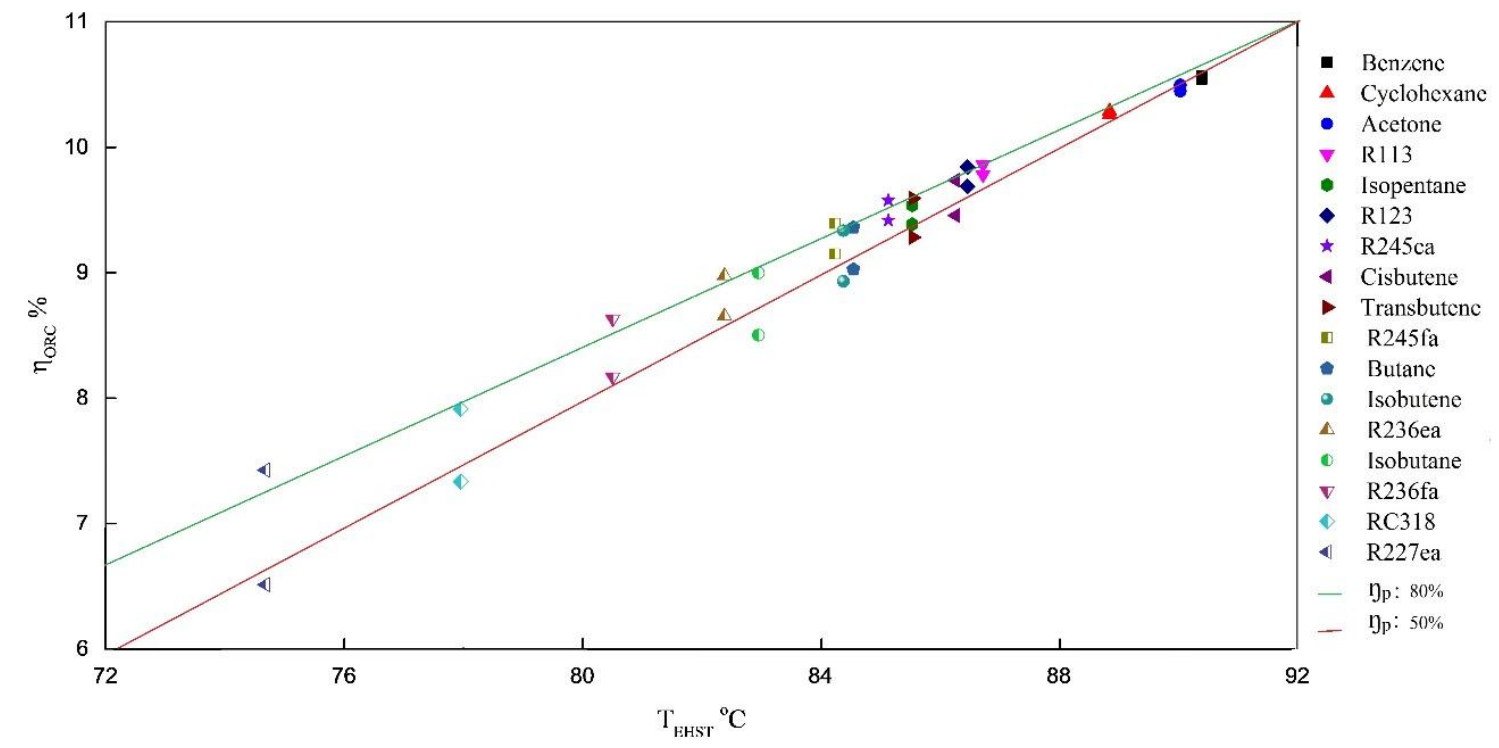

Fig. 6. Influence of $\mathrm{T}_{\mathrm{EHST}}$ of the working fluids on the ORC efficiency at pump efficiency of $50 \%$ and $80 \%$ 


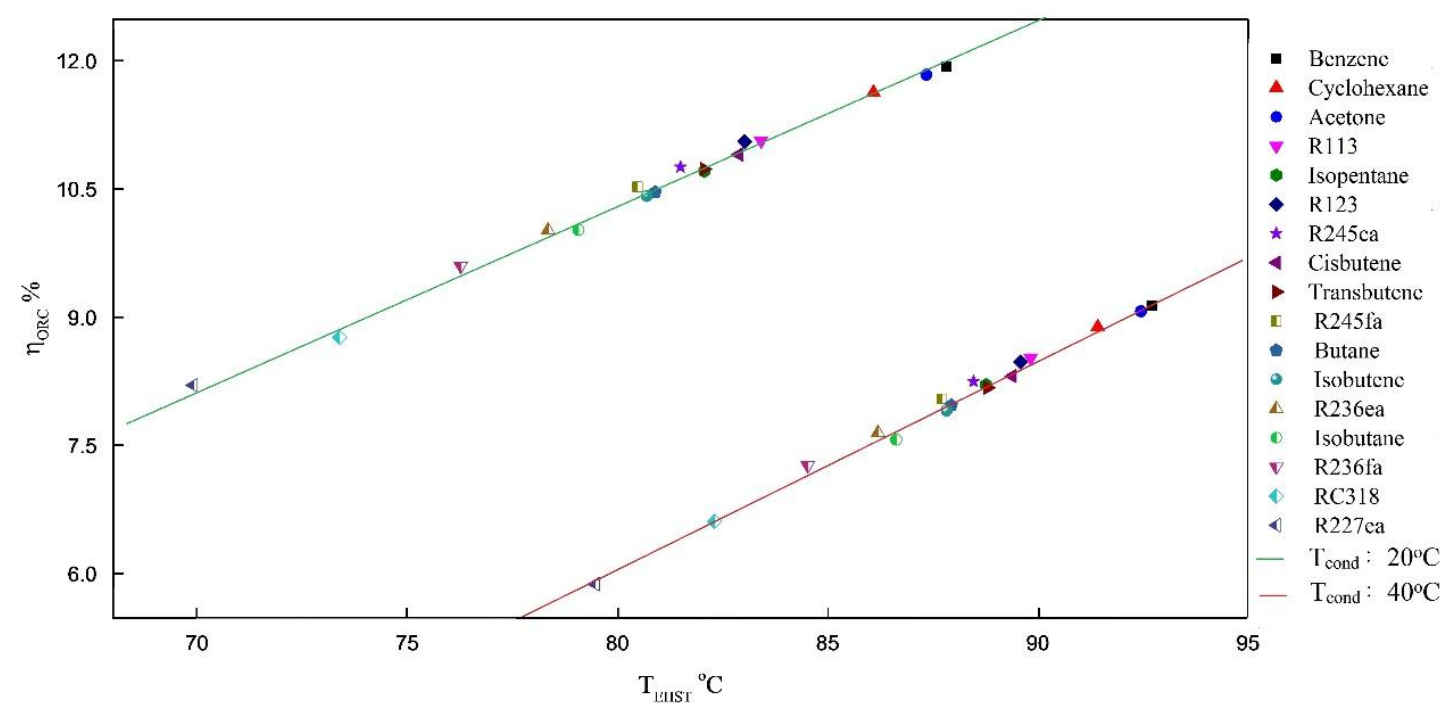

Fig. 7. Influence of $\mathrm{T}_{\mathrm{EHST}}$ of the working fluids on the ORC efficiency at condensation temperature of $20^{\circ} \mathrm{C}$ and $40^{\circ} \mathrm{C}$

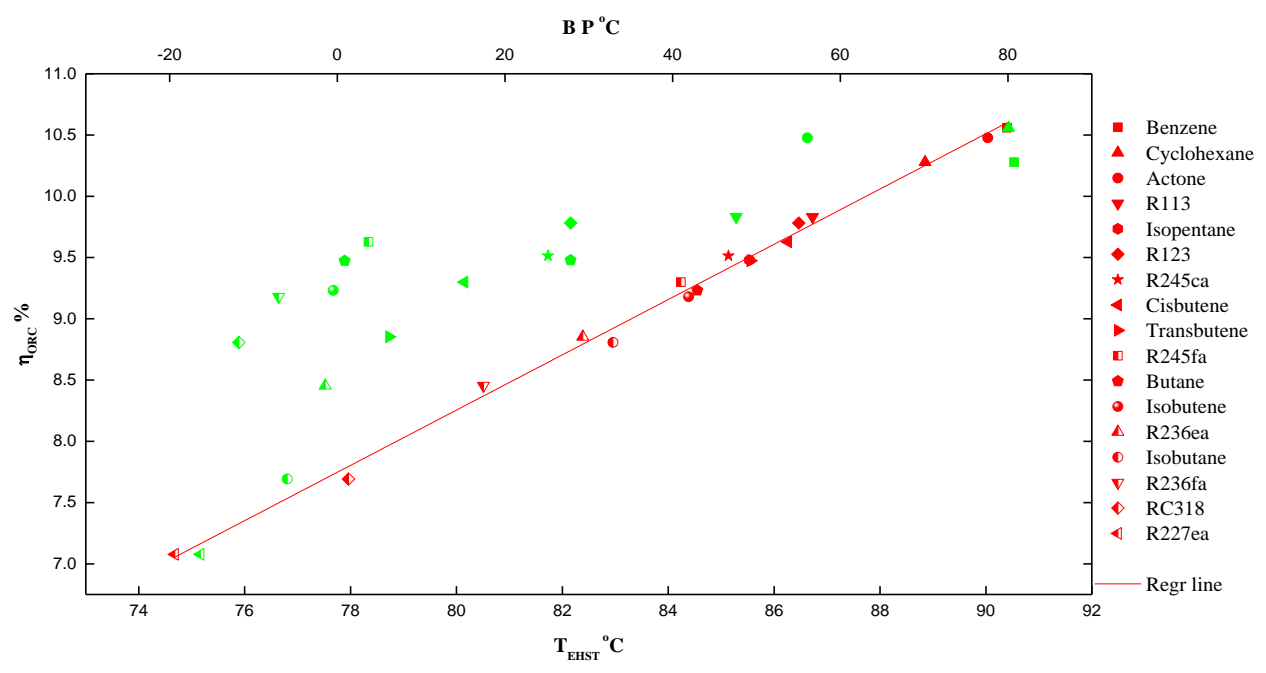

Fig. 8. Effects of $\mathrm{T}_{\mathrm{ESHT}}$ and boiling point temperature on the ORC efficiency of working fluids 


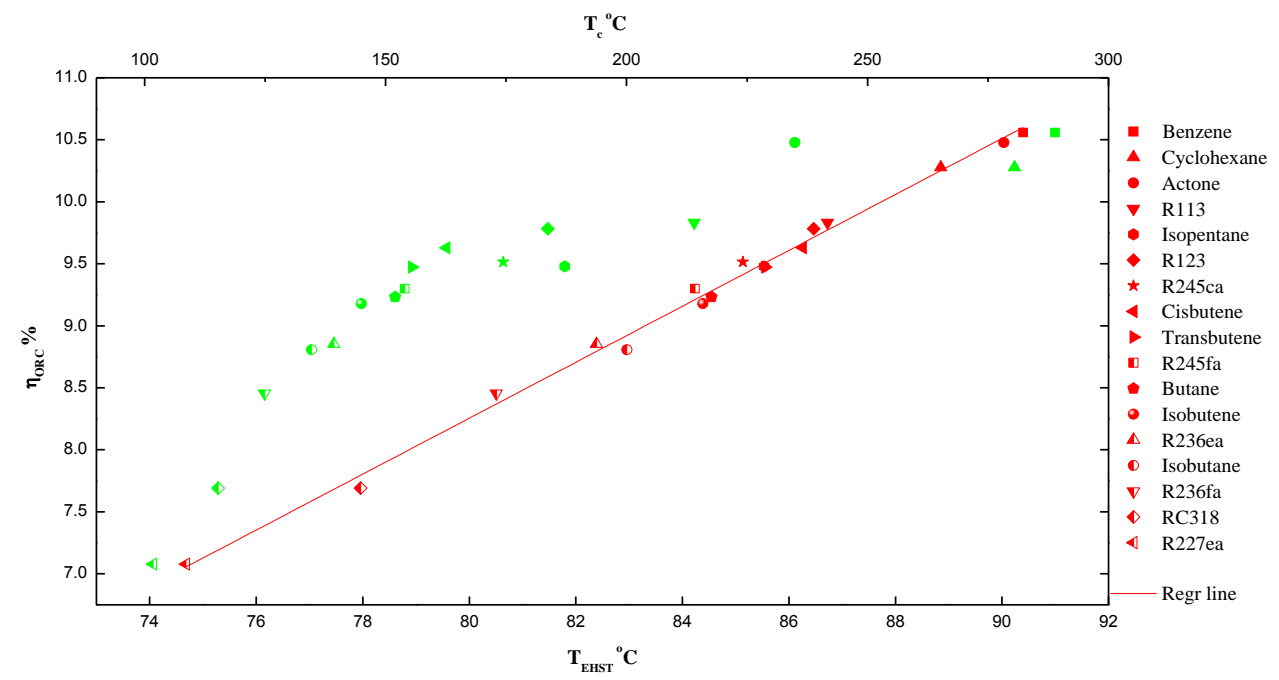

Fig. 9. Effects of $\mathrm{T}_{\mathrm{ESHT}}$ and critical temperature on the ORC efficiency of working fluids

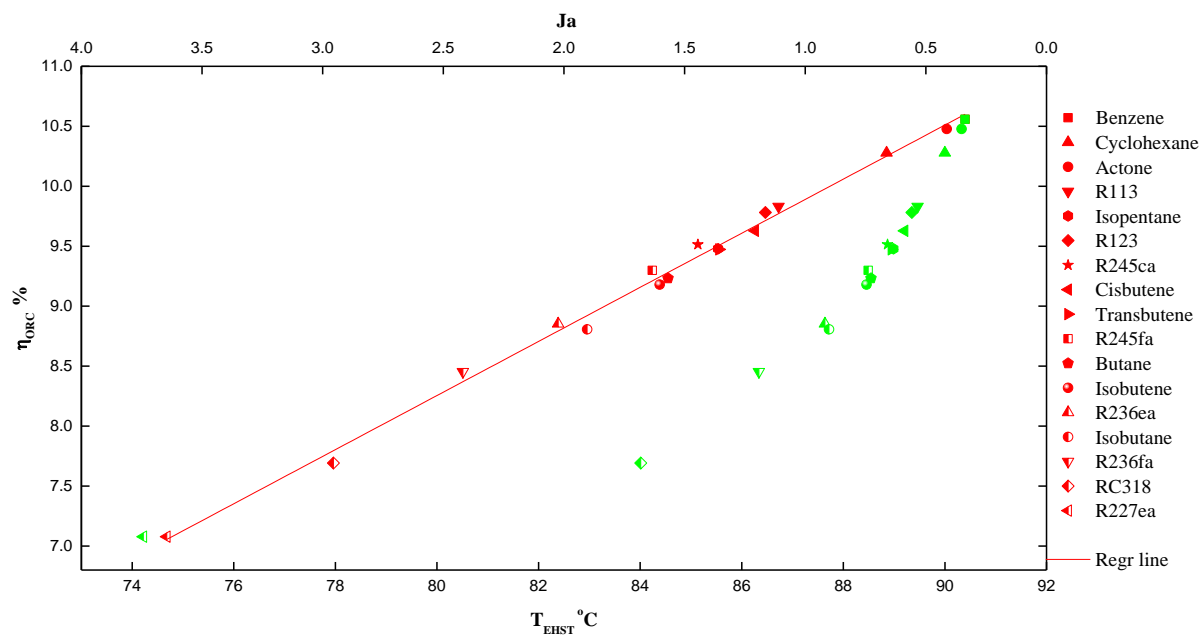

Fig. 10. Effects of $\mathrm{T}_{\mathrm{ESHT}}$ and Jacobs number on the ORC efficiency of working fluids 


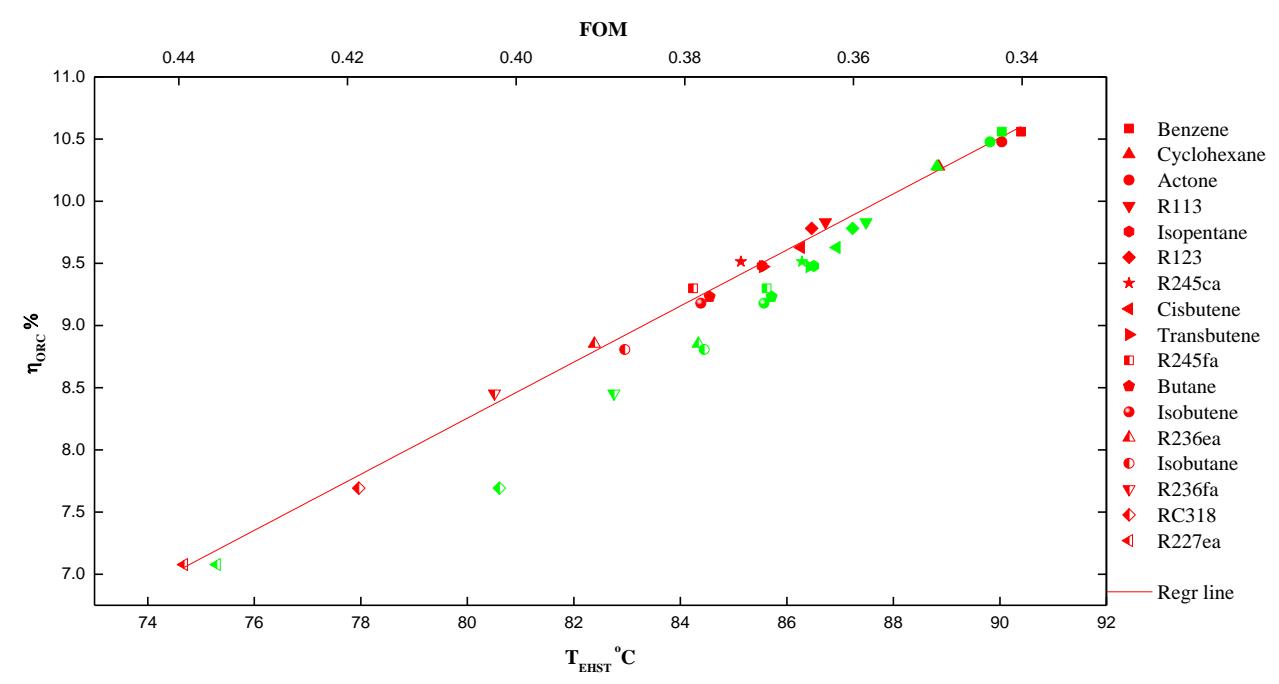

Fig.11. Effects of $\mathrm{T}_{\mathrm{ESHT}}$ and Figure of Merit on the ORC efficiency of working fluids at evaporation and condensation temperature of $100^{\circ} \mathrm{C}$ and $30^{\circ} \mathrm{C}$ respectively

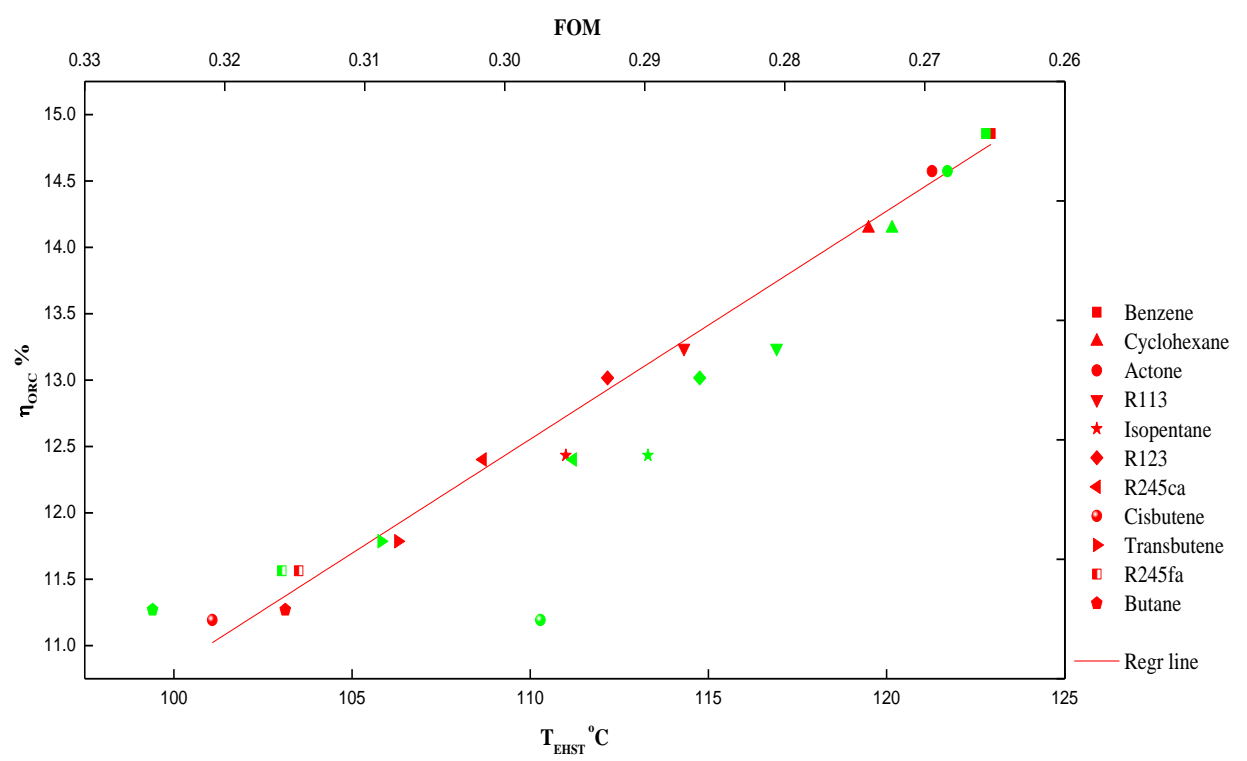

Fig. 12. Effects of TESHT and Figure of Merit on the ORC efficiency of working fluids at evaporation and condensation temperature of $150^{\circ} \mathrm{C}$ and $30^{\circ} \mathrm{C}$ respectively 
Table 1. $\mathrm{T}_{\text {EHST }}$ of the working fluids in the evaporation temperature range from $100{ }^{\circ} \mathrm{C}$ to $150^{\circ} \mathrm{C}$, unit: ${ }^{\circ} \mathrm{C}$

\begin{tabular}{|c|c|c|c|c|c|c|c|c|c|c|c|}
\hline \multirow[t]{2}{*}{ Fluid } & \multicolumn{11}{|c|}{ Evaporation temperature, ${ }^{\circ} \mathrm{C}$} \\
\hline & 100 & 105 & 110 & 115 & 120 & 125 & 130 & 135 & 140 & 145 & 150 \\
\hline Toluene & 90.1 & 93.7 & 97.2 & 100.6 & 104.0 & 107.3 & 110.5 & 113.6 & 116.7 & 119.7 & 122.6 \\
\hline Benzene & 90.4 & 94.0 & 97.5 & 101.0 & 104.3 & 107.6 & 110.8 & 114.0 & 117.0 & 120.0 & 122.9 \\
\hline Cyclohexane & 88.9 & 92.3 & 95.6 & 98.9 & 102.1 & 105.2 & 108.2 & 111.1 & 114.0 & 116.8 & 119.5 \\
\hline Cyclopentane & 89.1 & 92.6 & 95.9 & 99.2 & 102.3 & 105.4 & 108.4 & 111.3 & 114.1 & 116.9 & 119.5 \\
\hline Acetone & 90.0 & 93.6 & 97.0 & 100.4 & 103.6 & 106.8 & 109.9 & 112.9 & 115.8 & 118.6 & 121.3 \\
\hline R113 & 86.7 & 89.9 & 93.0 & 96.0 & 98.9 & 101.7 & 104.4 & 107.0 & 109.5 & 112.0 & 114.3 \\
\hline R141b & 88.0 & 91.3 & 94.5 & 97.6 & 100.6 & 103.5 & 106.3 & 109.0 & 111.6 & 114.0 & 116.4 \\
\hline R11 & 88.3 & 91.7 & 94.9 & 98.0 & 101.0 & 103.9 & 106.7 & 109.3 & 111.9 & 114.3 & 116.7 \\
\hline Pentane & 86.0 & 89.1 & 92.1 & 94.9 & 97.7 & 100.4 & 103.0 & 105.5 & 107.9 & 110.2 & 112.4 \\
\hline Isopentane & 85.5 & 88.5 & 91.5 & 94.3 & 97.0 & 99.6 & 102.1 & 104.5 & 106.8 & 108.9 & 111.0 \\
\hline R123 & 86.5 & 89.6 & 92.5 & 95.4 & 98.2 & 100.8 & 103.3 & 105.7 & 108.0 & 110.1 & 112.2 \\
\hline $\mathrm{R} 245 \mathrm{ca}$ & 85.1 & 88.1 & 90.9 & 93.6 & 96.1 & 98.6 & 100.9 & 103.1 & 105.1 & 107.0 & 108.7 \\
\hline Cisbutene & 86.3 & 89.3 & 92.1 & 94.9 & 97.5 & 99.9 & 102.2 & 104.3 & 106.2 & 107.9 & 109.3 \\
\hline Transbutene & 85.6 & 88.5 & 91.2 & 93.9 & 96.3 & 98.7 & 100.8 & 102.7 & 104.3 & 105.6 & 106.3 \\
\hline R245fa & 84.2 & 87.1 & 89.6 & 92.2 & 94.5 & 96.7 & 98.7 & 100.4 & 101.9 & 103.1 & 103.5 \\
\hline Butane & 84.5 & 87.3 & 90.0 & 92.5 & 94.9 & 97.0 & 99.0 & 100.8 & 102.3 & 103.3 & 103.1 \\
\hline Butene & 84.7 & 87.5 & 90.1 & 92.6 & 94.9 & 96.9 & 98.7 & 100.1 & 101.1 & 100.3 & \\
\hline R114 & 83.1 & 85.7 & 88.2 & 90.5 & 92.7 & 94.6 & 96.3 & 97.6 & 98.6 & 98.5 & \\
\hline
\end{tabular}




\begin{tabular}{|c|c|c|c|c|c|c|c|c|}
\hline Isobutene & 84.4 & 87.1 & 89.7 & 92.1 & 94.3 & 96.3 & 98.0 & 99.3 \\
\hline R236ea & 82.4 & 84.9 & 87.3 & 89.5 & 91.6 & 93.4 & 95.0 & 96.2 \\
\hline R142b & 84.2 & 86.9 & 89.3 & 91.6 & 93.5 & 95.2 & 96.3 & 96.3 \\
\hline Isobutane & 83.0 & 85.5 & 87.8 & 89.9 & 91.8 & 93.3 & 94.2 & \\
\hline R236fa & 80.5 & 82.6 & 84.4 & 85.8 & 86.5 & & & \\
\hline R124 & 81.5 & 83.7 & 85.6 & 86.9 & 87.2 & & & \\
\hline RC318 & 78.0 & 79.7 & 80.9 & & & & & \\
\hline R1234ze & 79.1 & 80.3 & & & & & & \\
\hline R227ea & 74.7 & & & & & & & \\
\hline
\end{tabular}


Table 2. Error caused by approximating the equivalent cold side temperature, unit: ${ }^{\circ} \mathrm{C}$

\begin{tabular}{|c|c|c|c|c|c|c|c|c|c|c|c|}
\hline \multirow[t]{2}{*}{ Fluid } & \multicolumn{11}{|c|}{ Evaporation temperature, ${ }^{\circ} \mathrm{C}$} \\
\hline & 100 & 105 & 110 & 115 & 120 & 125 & 130 & 135 & 140 & 145 & 150 \\
\hline Toluene & 0.01 & 0.03 & 0.05 & 0.08 & 0.11 & 0.15 & 0.20 & 0.27 & 0.34 & 0.41 & 0.50 \\
\hline Benzene & 0.00 & 0.00 & 0.00 & 0.00 & 0.00 & 0.00 & 0.00 & 0.00 & 0.01 & 0.02 & 0.04 \\
\hline Cyclohexane & 0.29 & 0.37 & 0.47 & 0.57 & 0.69 & 0.84 & 0.99 & 1.16 & 1.34 & 1.54 & 1.75 \\
\hline Cyclopentane & 0.03 & 0.04 & 0.07 & 0.09 & 0.13 & 0.17 & 0.22 & 0.28 & 0.33 & 0.40 & 0.48 \\
\hline Acetone & 0.00 & 0.00 & 0.00 & 0.00 & 0.00 & 0.00 & 0.00 & 0.00 & 0.00 & 0.00 & 0.00 \\
\hline R113 & 0.68 & 0.81 & 0.93 & 1.07 & 1.21 & 1.36 & 1.52 & 1.67 & 1.84 & 1.99 & 2.16 \\
\hline $\mathrm{R} 141 \mathrm{~b}$ & 0.05 & 0.05 & 0.06 & 0.08 & 0.08 & 0.10 & 0.12 & 0.14 & 0.15 & 0.17 & 0.19 \\
\hline R11 & 0.00 & 0.00 & 0.00 & 0.00 & 0.00 & 0.00 & 0.00 & 0.00 & 0.00 & 0.00 & 0.00 \\
\hline pentane & 0.98 & 1.15 & 1.32 & 1.51 & 1.71 & 1.92 & 2.14 & 2.36 & 2.58 & 2.81 & 3.03 \\
\hline Isopentane & 1.14 & 1.32 & 1.51 & 1.72 & 1.94 & 2.17 & 2.40 & 2.63 & 2.85 & 3.08 & 3.29 \\
\hline $\mathrm{R} 123$ & 0.20 & 0.23 & 0.27 & 0.31 & 0.35 & 0.39 & 0.41 & 0.46 & 0.47 & 0.50 & 0.49 \\
\hline $\mathrm{R} 245 \mathrm{ca}$ & 0.54 & 0.62 & 0.70 & 0.79 & 0.89 & 0.97 & 1.03 & 1.10 & 1.16 & 1.18 & 1.18 \\
\hline Cisbutene & 0.00 & 0.01 & 0.01 & 0.01 & 0.01 & 0.01 & 0.00 & 0.00 & 0.00 & 0.00 & 0.00 \\
\hline Transbutene & 0.07 & 0.08 & 0.09 & 0.09 & 0.08 & 0.08 & 0.06 & 0.05 & 0.02 & 0.00 & 0.00 \\
\hline R245fa & 0.37 & 0.42 & 0.45 & 0.49 & 0.53 & 0.54 & 0.54 & 0.52 & 0.44 & 0.34 & 0.16 \\
\hline Butane & 0.39 & 0.43 & 0.48 & 0.52 & 0.54 & 0.55 & 0.54 & 0.50 & 0.42 & 0.28 & 0.05 \\
\hline Butene & 0.05 & 0.05 & 0.05 & 0.04 & 0.03 & 0.02 & 0.01 & 0.00 & 0.00 & & \\
\hline R114 & 0.77 & 0.84 & 0.91 & 0.95 & 0.96 & 0.97 & 0.91 & 0.81 & 0.59 & & \\
\hline Isobutene & 0.09 & 0.10 & 0.11 & 0.10 & 0.08 & 0.06 & 0.03 & 0.00 & 0.00 & & \\
\hline R236ea & 0.79 & 0.86 & 0.93 & 0.99 & 1.02 & 1.02 & 0.99 & & & & \\
\hline $\mathrm{R} 142 \mathrm{~b}$ & 0.01 & 0.02 & 0.02 & 0.01 & 0.02 & 0.01 & 0.01 & & & & \\
\hline Isobutane & 0.32 & 0.33 & 0.33 & 0.31 & 0.27 & 0.19 & 0.07 & & & & \\
\hline R236fa & 0.45 & 0.42 & 0.35 & 0.23 & 0.06 & & & & & & \\
\hline R124 & 0.00 & 0.00 & 0.00 & 0.00 & 0.00 & & & & & & \\
\hline
\end{tabular}




$\begin{array}{llll}\text { R318 } & 1.66 & 1.62 & 1.37 \\ \text { R1234ze } & 0.00 & & \\ \text { R227ea } & 0.00 & & \\ & & & \end{array}$


Table 3. Relative error in approximating the heat input, unit:\%

\begin{tabular}{|c|c|c|c|c|c|c|c|c|c|c|c|}
\hline \multirow[t]{2}{*}{ Fluid } & \multicolumn{11}{|c|}{ Evaporation temperature, ${ }^{\circ} \mathrm{C}$} \\
\hline & 100 & 105 & 110 & 115 & 120 & 125 & 130 & 135 & 140 & 145 & 150 \\
\hline Toluene & 0.02 & 0.02 & 0.02 & 0.03 & 0.03 & 0.03 & 0.04 & 0.04 & 0.05 & 0.05 & 0.05 \\
\hline Benzene & 0.04 & 0.04 & 0.05 & 0.05 & 0.06 & 0.07 & 0.08 & 0.09 & 0.09 & 0.10 & 0.11 \\
\hline Cyclohexane & 0.04 & 0.05 & 0.05 & 0.06 & 0.07 & 0.08 & 0.08 & 0.09 & 0.10 & 0.11 & 0.12 \\
\hline Cyclopentane & 0.10 & 0.12 & 0.13 & 0.14 & 0.16 & 0.18 & 0.19 & 0.21 & 0.23 & 0.26 & 0.28 \\
\hline Acetone & 0.06 & 0.07 & 0.08 & 0.09 & 0.10 & 0.12 & 0.13 & 0.15 & 0.17 & 0.18 & 0.20 \\
\hline R113 & 0.12 & 0.14 & 0.15 & 0.17 & 0.19 & 0.21 & 0.23 & 0.25 & 0.28 & 0.31 & 0.34 \\
\hline $\mathrm{R} 141 \mathrm{~b}$ & 0.18 & 0.20 & 0.22 & 0.25 & 0.28 & 0.31 & 0.33 & 0.37 & 0.40 & 0.43 & 0.47 \\
\hline R11 & 0.22 & 0.25 & 0.28 & 0.31 & 0.34 & 0.38 & 0.42 & 0.45 & 0.50 & 0.55 & 0.59 \\
\hline pentane & 0.18 & 0.20 & 0.22 & 0.24 & 0.27 & 0.29 & 0.32 & 0.35 & 0.38 & 0.41 & 0.45 \\
\hline Isopentane & 0.22 & 0.25 & 0.28 & 0.30 & 0.33 & 0.37 & 0.40 & 0.43 & 0.47 & 0.51 & 0.56 \\
\hline $\mathrm{R} 123$ & 0.22 & 0.25 & 0.28 & 0.31 & 0.34 & 0.38 & 0.42 & 0.46 & 0.50 & 0.55 & 0.60 \\
\hline R245ca & 0.23 & 0.26 & 0.29 & 0.33 & 0.36 & 0.40 & 0.44 & 0.48 & 0.53 & 0.59 & 0.64 \\
\hline Cisbutene & 0.41 & 0.46 & 0.51 & 0.57 & 0.62 & 0.69 & 0.75 & 0.83 & 0.91 & 0.99 & 1.09 \\
\hline Transbutene & 0.46 & 0.51 & 0.56 & 0.62 & 0.69 & 0.76 & 0.83 & 0.91 & 1.00 & 1.11 & 1.24 \\
\hline R245fa & 0.36 & 0.40 & 0.45 & 0.50 & 0.55 & 0.61 & 0.67 & 0.73 & 0.81 & 0.90 & 1.01 \\
\hline Butane & 0.49 & 0.55 & 0.61 & 0.67 & 0.73 & 0.80 & 0.88 & 0.97 & 1.06 & 1.17 & 1.32 \\
\hline Butene & 0.58 & 0.64 & 0.71 & 0.79 & 0.87 & 0.96 & 1.06 & 1.17 & 1.31 & & \\
\hline R114 & 0.50 & 0.55 & 0.61 & 0.68 & 0.75 & 0.82 & 0.91 & 1.01 & 1.11 & & \\
\hline Isobutene & 0.59 & 0.66 & 0.73 & 0.80 & 0.89 & 0.98 & 1.08 & 1.20 & 1.34 & & \\
\hline R236ea & 0.47 & 0.53 & 0.59 & 0.65 & 0.73 & 0.80 & 0.88 & & & & \\
\hline $\mathrm{R} 142 \mathrm{~b}$ & 0.66 & 0.74 & 0.82 & 0.92 & 1.02 & 1.13 & 1.27 & & & & \\
\hline Isobutane & 1.52 & 1.57 & 1.62 & 1.67 & 1.71 & 1.75 & 1.78 & & & & \\
\hline R236fa & 0.67 & 0.75 & 0.85 & 0.96 & 1.10 & & & & & & \\
\hline R124 & 0.84 & 0.95 & 1.07 & 1.21 & 1.41 & & & & & & \\
\hline
\end{tabular}




\begin{tabular}{llll} 
R318 & 0.83 & 0.93 & 1.05 \\
R1234ze & 1.16 & & \\
R227ea & 1.30 & & \\
\hline
\end{tabular}


Table 4. Some properties of the working fluids [52-61]

\begin{tabular}{|c|c|c|c|c|c|c|}
\hline Fluid & $\begin{array}{c}\text { Molecular } \\
\text { weight }\end{array}$ & $\begin{array}{c}\text { Critical } \\
\text { temperature, } \\
{ }^{\circ} \mathrm{C}\end{array}$ & $\begin{array}{l}\text { Critical } \\
\text { pressure, } \\
\mathrm{MPa}\end{array}$ & A & B & $\mathrm{C}$ \\
\hline Toluene & 92.1384 & 319.85 & 4.10 & 4.08245 & 1346.382 & -53.508 \\
\hline Benzene & 78.1 & 288.9 & 4.894 & 4.72583 & 1660.652 & -1.461 \\
\hline Cyclohexane & 84.1595 & 280.49 & 4.075 & 4.13983 & 1316.554 & -35.581 \\
\hline Cyclopentane & 70.1329 & 238.45 & 4.51 & 4.00288 & 1119.208 & -42.412 \\
\hline Acetone & 58.0791 & 234.95 & 4.7 & 4.42448 & 1312.253 & -32.445 \\
\hline R113 & 187.376 & 214.06 & 3.392 & 4.02936 & 1112.856 & -44.119 \\
\hline $\mathrm{R} 141 \mathrm{~b}$ & 116.950 & 204.35 & 4.194 & 4.020 & 1063.376 & -40.736 \\
\hline R11 & 137.368 & 197.95 & 4.466 & 4.01447 & 1043.303 & -36.602 \\
\hline Pentane & 72.1488 & 196.65 & 3.36 & 3.9892 & 1070.617 & -40.454 \\
\hline Isopentane & 72.1488 & 187.2 & 3.378 & 3.97183 & 1021.864 & -43.231 \\
\hline R123 & 152.9 & 183.68 & 3.6618 & 4.0222 & 1034.145 & -44.747 \\
\hline $\mathrm{R} 245 \mathrm{ca}$ & 134.0479 & 174.42 & 3.925 & & & \\
\hline Cisbutene & 170.0289 & 162.6 & 4.225 & 3.98744 & 957.06 & -36.504 \\
\hline Transbutene & 56.1063 & 155.46 & 4.027 & 4.0436 & 982.166 & -30.775 \\
\hline R245fa & 134.0479 & 154.01 & 3.651 & 4.1823 & 997.2 & -48.765 \\
\hline Butane & 58.1222 & 151 & 3.796 & 4.70812 & 1200.475 & -13.013 \\
\hline Butene & 56.1063 & 146.35 .98 & 4.02 & 4.24696 & 1099.207 & -8.256 \\
\hline R114 & 170.921 & 145.7 & 3.393 & 4.15162 & 1031.026 & -27.911 \\
\hline Isobutene & 56.1063 & 144.94 & 4.009 & 3.64709 & 799.055 & -46.615 \\
\hline R236ea & 152.0384 & 139.29 & 3.502 & & & \\
\hline $\mathrm{R} 142 \mathrm{~b}$ & 100.495 & 137.05 & 4.048 & 4.007 & 916.0158 & -35.5111 \\
\hline Isobutane & 58.1222 & 134.66 & 3.629 & 4.3281 & 1132.108 & 0.918 \\
\hline R236fa & 152.0384 & 124.92 & 3.2 & 4.255888 & 1004.490 & -35.332 \\
\hline
\end{tabular}




\begin{tabular}{|c|c|c|c|c|c|c|}
\hline $\mathrm{R} 124$ & 136.476 & 122.2 & 3.615 & & & \\
\hline R318 & 200.0300 & 115.23 & 2.777 & 4.254 & 1007.399 & -30.205 \\
\hline R1234ze & 114.04 & 109.37 & 3.6363 & & & \\
\hline R227ea & 170.0289 & 101.75 & 2.925 & & & \\
\hline
\end{tabular}


Table 5. Estimated $a$-value of the working fluids in the evaporation temperature range from $100^{\circ} \mathrm{C}$ to $150^{\circ} \mathrm{C}$, unit: $\%$

\begin{tabular}{|c|c|c|c|c|c|c|c|c|c|c|c|}
\hline \multirow[t]{2}{*}{ Fluid } & \multicolumn{11}{|c|}{ Evaporation temperature, ${ }^{\circ} \mathrm{C}$} \\
\hline & 100 & 105 & 110 & 115 & 120 & 125 & 130 & 135 & 140 & 145 & 150 \\
\hline Toluene & 0.05 & 0.06 & 0.07 & 0.08 & 0.09 & 0.10 & 0.12 & 0.14 & 0.15 & 0.17 & 0.19 \\
\hline Benzene & 0.22 & 0.24 & 0.26 & 0.29 & 0.31 & 0.34 & 0.37 & 0.40 & 0.43 & 0.46 & 0.50 \\
\hline Cyclohexane & 0.27 & 0.30 & 0.32 & 0.35 & 0.38 & 0.41 & 0.45 & 0.48 & 0.52 & 0.56 & 0.60 \\
\hline Cyclopentane & 0.62 & 0.66 & 0.71 & 0.76 & 0.82 & 0.88 & 0.93 & 1.00 & 1.05 & 1.15 & 1.24 \\
\hline Acetone & 0.42 & 0.46 & 0.50 & 0.54 & 0.59 & 0.64 & 0.69 & 0.74 & 0.80 & 0.86 & 0.92 \\
\hline R113 & 0.86 & 0.93 & 1.00 & 1.07 & 1.15 & 1.23 & 1.32 & 1.42 & 1.52 & 1.62 & 1.73 \\
\hline $\mathrm{R} 141 \mathrm{~b}$ & 0.96 & 1.07 & 1.18 & 1.30 & 1.42 & 1.55 & 1.66 & 1.77 & 1.89 & 2.01 & 2.14 \\
\hline R11 & 1.35 & 1.44 & 1.55 & 1.65 & 1.76 & 1.89 & 2.04 & 2.17 & 2.30 & 2.45 & 2.61 \\
\hline Pentane & 1.09 & 1.20 & 1.29 & 1.37 & 1.47 & 1.56 & 1.66 & 1.77 & 1.88 & 2.00 & 2.23 \\
\hline Isopentane & 1.55 & 1.66 & 1.77 & 1.89 & 2.02 & 2.16 & 2.30 & 2.45 & 2.62 & 2.79 & 2.97 \\
\hline R123 & 1.47 & 1.57 & 1.69 & 1.81 & 1.94 & 2.08 & 2.22 & 2.37 & 2.54 & 2.71 & 2.89 \\
\hline $\mathrm{R} 245 \mathrm{ca}$ & 1.59 & 1.71 & 1.85 & 1.99 & 2.14 & 2.30 & 2.47 & 2.65 & 2.84 & 3.05 & 3.27 \\
\hline Cisbutene & 2.63 & 2.81 & 2.99 & 3.19 & 3.40 & 3.62 & 3.85 & 4.10 & 4.36 & 4.65 & 4.95 \\
\hline Transbutene & 2.95 & 3.14 & 3.35 & 3.57 & 3.81 & 4.06 & 4.32 & 4.61 & 4.91 & 5.24 & 5.61 \\
\hline R245fa & 2.38 & 2.56 & 2.75 & 2.96 & 3.18 & 3.42 & 3.67 & 3.95 & 4.24 & 4.56 & 4.91 \\
\hline Butane & 3.28 & 3.49 & 3.72 & 3.97 & 4.22 & 4.50 & 4.79 & 5.11 & 5.44 & 5.81 & 6.22 \\
\hline Butene & 3.72 & 3.96 & 4.21 & 4.49 & 4.78 & 5.04 & 5.42 & 5.86 & 6.43 & 7.40 & \\
\hline R114 & 3.76 & 4.00 & 4.26 & 4.53 & 4.83 & 5.15 & 5.49 & 5.86 & 6.26 & 6.71 & \\
\hline Isobutene & 3.86 & 4.11 & 4.38 & 4.66 & 4.97 & 5.29 & 5.64 & 6.02 & 6.44 & & \\
\hline R236ea & 3.38 & 3.63 & 3.90 & 4.18 & 4.49 & 4.83 & 5.18 & 5.57 & & & \\
\hline $\mathrm{R} 142 \mathrm{~b}$ & 4.15 & 4.43 & 4.73 & 5.05 & 5.40 & 5.78 & 6.19 & 6.65 & & & \\
\hline Isobutane & 4.85 & 5.17 & 5.50 & 5.86 & 6.25 & 6.67 & 7.13 & & & & \\
\hline R236fa & 4.73 & 5.10 & 5.51 & 5.96 & 6.46 & & & & & & \\
\hline
\end{tabular}




\begin{tabular}{llllll} 
R124 & 5.54 & 5.95 & 6.39 & 6.87 & 7.41 \\
RC318 & 6.31 & 6.80 & 7.36 & & \\
R1234ze & 7.40 & 8.63 & & \\
R227ea & 9.07 & & & \\
\hline
\end{tabular}


Table 6. Estimated efficiency of the working fluids, unit: \%

\begin{tabular}{|c|c|c|c|c|c|c|c|c|c|c|c|c|}
\hline \multirow[t]{3}{*}{ Fluids } & \multicolumn{12}{|c|}{ Evaporation temperature, ${ }^{\circ} \mathrm{C}$} \\
\hline & \multicolumn{2}{|c|}{100} & \multicolumn{2}{|c|}{110} & \multicolumn{2}{|c|}{120} & \multicolumn{2}{|c|}{130} & \multicolumn{2}{|c|}{140} & \multicolumn{2}{|c|}{150} \\
\hline & $\eta_{t, E H S T}$ & $\mu\left(\eta_{t}\right)$ & $\eta_{t, E H S T}$ & $\mu\left(\eta_{t}\right)$ & $\eta_{t, E H S T}$ & $\mu\left(\eta_{t}\right)$ & $\eta_{t, E H S T}$ & $\mu\left(\eta_{t}\right)$ & $\eta_{t, E H S T}$ & $\mu\left(\eta_{t}\right)$ & $\eta_{t, E H S T}$ & $\mu\left(\eta_{t}\right)$ \\
\hline Toluene & 10.5 & 0.07 & 11.5 & 0.12 & 12.4 & 0.2 & 13.3 & 0.29 & 14.1 & 0.43 & 14.8 & 0.56 \\
\hline Benzene & 10.6 & 0.0 & 11.6 & 0.0 & 12.5 & 0.0 & 13.4 & 0.0 & 14.1 & 0.0 & 14.9 & 0.0 \\
\hline $\begin{array}{l}\text { Cyclo- } \\
\text { hexane }\end{array}$ & 10.3 & 0.4 & 11.3 & 0.7 & 12.2 & 0.9 & 13.0 & 1.2 & 13.7 & 1.5 & 14.4 & 1.8 \\
\hline $\begin{array}{l}\text { Cyclo- } \\
\text { pentane }\end{array}$ & 10.3 & 0.21 & 11.2 & 0.26 & 12.1 & 0.23 & 12.9 & 0.25 & 13.3 & 0.27 & 13.6 & 0.28 \\
\hline Acetone & 10.5 & 0.0 & 11.5 & 0.0 & 12.4 & -0.1 & 13.2 & -0.1 & 13.9 & -0.1 & 14.6 & -0.1 \\
\hline R113 & 9.9 & 1.0 & 10.8 & 1.2 & 11.6 & 1.5 & 12.3 & 1.7 & 13.0 & 1.9 & 13.5 & 2.2 \\
\hline $\mathrm{R} 141 \mathrm{~b}$ & 10.1 & 0.22 & 11.0 & 0.09 & 11.8 & 0.05 & 12.5 & 0.0 & 13.1 & 0.0 & 13.7 & 0.0 \\
\hline $\mathrm{R} 11$ & 10.1 & 0.00 & 11.0 & -0.1 & 11.7 & -0.2 & 12.4 & -0.2 & 13.1 & -0.3 & 13.6 & -0.3 \\
\hline Pentane & 9.79 & 1.74 & 10.6 & 1.99 & 11.3 & 2.27 & 12.0 & 2.62 & 12.6 & 2.94 & 13.1 & 3.22 \\
\hline $\begin{array}{l}\text { Iso- } \\
\text { pentane }\end{array}$ & 9.7 & 1.8 & 10.5 & 2.2 & 11.2 & 2.6 & 11.8 & 2.9 & 12.4 & 3.2 & 12.9 & 3.4 \\
\hline R123 & 9.8 & 0.2 & 10.6 & 0.2 & 11.4 & 0.2 & 12.0 & 0.2 & 12.6 & 0.1 & 13.0 & 0.0 \\
\hline $\mathrm{R} 245 \mathrm{ca}$ & 9.6 & 0.8 & 10.4 & 0.9 & 11.1 & 1.0 & 11.6 & 1.0 & 12.1 & 1.0 & 12.5 & 0.9 \\
\hline Cis-butene & 9.6 & -0.3 & 10.4 & -0.4 & 11.0 & -0.4 & 11.6 & -0.5 & 12.0 & -0.6 & 12.2 & -0.5 \\
\hline $\begin{array}{l}\text { Trans- } \\
\text { butene }\end{array}$ & 9.4 & -0.3 & 10.2 & -0.3 & 10.8 & -0.4 & 11.3 & -0.5 & 11.6 & -0.6 & 11.7 & -0.4 \\
\hline $\mathrm{R} 245 \mathrm{fa}$ & 9.3 & 0.5 & 10.1 & 0.4 & 10.7 & 0.4 & 11.1 & 0.2 & 11.5 & -0.1 & 11.5 & -0.3 \\
\hline Butane & 9.3 & 0.3 & 10.0 & 0.2 & 10.5 & 0.1 & 11.0 & -0.1 & 11.3 & -0.3 & 11.2 & -0.4 \\
\hline Butene & 9.22 & -0.3 & 9.89 & -0.4 & 10.4 & -0.5 & 10.8 & -0.6 & 10.9 & -0.7 & & \\
\hline R114 & 8.98 & 0.39 & 9.62 & 0.35 & 10.1 & 0.19 & 10.5 & -0.1 & 10.6 & -0.7 & & \\
\hline
\end{tabular}




$\begin{array}{lcccccccccc}\text { Isobutene } & 9.1 & -0.3 & 9.8 & -0.4 & 10.3 & -0.6 & 10.7 & -0.7 & 10.8 & -0.4 \\ \text { R236ea } & 8.9 & 0.9 & 9.6 & 0.9 & 10.0 & 0.7 & 10.4 & 0.4 & \\ \text { R142b } & 9.08 & -0.2 & 9.70 & -0.3 & 10.1 & -0.2 & 10.3 & 0.08 & \\ \text { Isobutane } & 8.8 & -0.1 & 9.4 & -0.3 & 9.8 & -0.5 & 9.9 & -0.6 & \\ \text { R236fa } & 8.5 & 0.1 & 8.9 & -0.2 & 9.0 & -0.3 & & & \\ \text { R124 } & 8.5 & -0.6 & 8.9 & -0.5 & 9.0 & 0.6 & & & \\ \text { RC318 } & 7.9 & 2.4 & 8.1 & 1.5 & & & & & \\ \text { R1234ze } & 7.89 & -0.1 & & & & & & & & \end{array}$


Table 7. $\mathrm{T}_{\text {EHST }}$ of the working fluids with a degree of superheat of $5^{\circ} \mathrm{C}$ at the expander inlet, unit: ${ }^{\circ} \mathrm{C}$

\begin{tabular}{|c|c|c|c|c|c|c|c|c|c|c|c|}
\hline \multirow[t]{2}{*}{ Fluid } & \multicolumn{11}{|c|}{ Evaporation temperature, ${ }^{\circ} \mathrm{C}$} \\
\hline & 100 & 105 & 110 & 115 & 120 & 125 & 130 & 135 & 140 & 145 & 150 \\
\hline Toluene & 90.3 & 93.9 & 97.5 & 100.9 & 104.3 & 107.6 & 110.8 & 114.0 & 117.1 & 120.1 & 123.1 \\
\hline Benzene & 90.4 & 94.0 & 97.6 & 101.0 & 104.4 & 107.7 & 110.9 & 114.0 & 117.1 & 120.1 & 123.1 \\
\hline Cyclohexane & 89.1 & 92.6 & 95.9 & 99.2 & 102.4 & 105.5 & 108.6 & 111.6 & 114.5 & 117.3 & 120.0 \\
\hline Cyclopentane & 89.4 & 92.9 & 96.2 & 99.5 & 102.7 & 105.8 & 108.8 & 111.8 & 114.7 & 117.4 & 120.1 \\
\hline Acetone & 90.2 & 93.8 & 97.2 & 100.6 & 103.9 & 107.1 & 110.2 & 113.2 & 116.2 & 119.0 & 121.8 \\
\hline $\mathrm{R} 113$ & 87.0 & 90.3 & 93.4 & 96.4 & 99.3 & 102.2 & 104.9 & 107.6 & 110.1 & 112.6 & 115.1 \\
\hline $\mathrm{R} 141 \mathrm{~b}$ & 88.3 & 91.6 & 94.8 & 98.0 & 101.0 & 103.9 & 106.8 & 109.5 & 112.1 & 114.7 & 117.1 \\
\hline R11 & 88.6 & 92.0 & 95.3 & 98.4 & 101.4 & 104.4 & 107.2 & 109.9 & 112.5 & 115.0 & 117.4 \\
\hline Pentane & 86.4 & 89.5 & 92.6 & 95.5 & 98.3 & 101.1 & 103.7 & 106.2 & 108.7 & 111.1 & 113.3 \\
\hline Isopentane & 85.9 & 89.0 & 92.0 & 94.8 & 97.6 & 100.2 & 102.8 & 105.2 & 107.6 & 109.9 & 112.1 \\
\hline R123 & 86.7 & 89.9 & 92.9 & 95.8 & 98.6 & 101.3 & 103.9 & 106.4 & 108.8 & 111.0 & 113.2 \\
\hline $\mathrm{R} 245 \mathrm{ca}$ & 85.5 & 88.5 & 91.4 & 94.1 & 96.8 & 99.3 & 101.7 & 103.9 & 106.1 & 108.1 & 110.0 \\
\hline Cisbutene & 86.6 & 89.7 & 92.6 & 95.4 & 98.1 & 100.6 & 103.0 & 105.3 & 107.4 & 109.3 & 111.0 \\
\hline Transbutene & 86.0 & 89.0 & 91.8 & 94.5 & 97.1 & 99.5 & 101.8 & 103.9 & 105.8 & 107.5 & 109.0 \\
\hline $\mathrm{R} 245 \mathrm{fa}$ & 84.7 & 87.5 & 90.3 & 92.8 & 95.3 & 97.6 & 99.7 & 101.7 & 103.5 & 105.1 & 106.5 \\
\hline Butane & 85.0 & 87.9 & 90.6 & 93.2 & 95.7 & 98.0 & 100.2 & 102.2 & 104.0 & 105.6 & 107.0 \\
\hline Butene & 85.3 & 88.1 & 90.8 & 93.4 & 95.8 & 98.0 & 100.1 & 101.9 & 103.6 & 104.9 & 85.3 \\
\hline R114 & 83.7 & 86.4 & 89.0 & 91.4 & 93.7 & 95.8 & 97.7 & 99.5 & 101.0 & 102.3 & 83.7 \\
\hline
\end{tabular}




\begin{tabular}{|c|c|c|c|c|c|c|c|c|}
\hline Isobutene & 84.9 & 87.7 & 90.4 & 92.9 & 95.3 & 97.4 & 99.5 & 101.2 \\
\hline R236ea & 83.0 & 85.6 & 88.1 & 90.4 & 92.6 & 94.7 & 96.6 & 98.2 \\
\hline $\mathrm{R} 142 \mathrm{~b}$ & 84.8 & 87.5 & 90.1 & 92.5 & 94.7 & 96.7 & 98.4 & 99.8 \\
\hline Isobutane & 83.6 & 86.2 & 88.7 & 91.0 & 93.1 & 95.1 & 96.8 & \\
\hline R236fa & 81.3 & 83.6 & 85.7 & 87.6 & 89.2 & & & \\
\hline R124 & 82.4 & 84.8 & 87.0 & 88.9 & 90.5 & & & \\
\hline R318 & 79.1 & 81.2 & 83.0 & & & & & \\
\hline R1234ze & 80.6 & 82.6 & & & & & & \\
\hline R227ea & 77.6 & & & & & & & \\
\hline
\end{tabular}


Table 8. Estimated efficiency of the working fluids with a degree of superheat of $5{ }^{\circ} \mathrm{C}$ at the expander inlet, unit: \%

\begin{tabular}{|c|c|c|c|c|c|c|c|c|c|c|c|c|}
\hline \multirow[t]{3}{*}{ Fluids } & \multicolumn{12}{|c|}{ Evaporation temperature, ${ }^{\circ} \mathrm{C}$} \\
\hline & \multicolumn{2}{|c|}{100} & \multicolumn{2}{|c|}{110} & \multicolumn{2}{|c|}{120} & \multicolumn{2}{|c|}{130} & \multicolumn{2}{|c|}{140} & \multicolumn{2}{|c|}{150} \\
\hline & $\eta_{t, E H S T}$ & $\mu\left(\eta_{t}\right)$ & $\eta_{t, E H S T}$ & $\mu\left(\eta_{t}\right)$ & $\eta_{t, E H S T}$ & $\mu\left(\eta_{t}\right)$ & $\eta_{t, E H S T}$ & $\mu\left(\eta_{t}\right)$ & $\eta_{t, E H S T}$ & $\mu\left(\eta_{t}\right)$ & $\eta_{t, E H S T}$ & $\mu\left(\eta_{t}\right)$ \\
\hline Toluene & 10.6 & 0.2 & 11.6 & 0.3 & 12.5 & 0.4 & 13.4 & 0.6 & 14.2 & 0.7 & 14.9 & 0.9 \\
\hline Benzene & 10.6 & 0.0 & 11.6 & 0.0 & 12.5 & 0.0 & 13.4 & 0.0 & 14.1 & 0.0 & 14.9 & 0.1 \\
\hline $\begin{array}{l}\text { Cyclo- } \\
\text { hexane }\end{array}$ & 10.4 & 0.9 & 11.3 & 1.2 & 12.2 & 1.4 & 13.0 & 1.8 & 13.8 & 2.1 & 14.5 & 2.5 \\
\hline $\begin{array}{l}\text { Cyclo- } \\
\text { pentane }\end{array}$ & 10.4 & 0.2 & 11.3 & 0.3 & 12.2 & 0.4 & 13.0 & 0.5 & 13.7 & 0.6 & 14.3 & 0.7 \\
\hline Acetone & 10.5 & 0.0 & 11.5 & -0.1 & 12.4 & -0.1 & 13.2 & -0.1 & 13.9 & -0.1 & 14.6 & -0.1 \\
\hline R113 & 10.0 & 1.7 & 10.9 & 1.9 & 11.7 & 2.2 & 12.4 & 2.5 & 13.0 & 2.7 & 13.6 & 2.9 \\
\hline $\mathrm{R} 141 \mathrm{~b}$ & 10.1 & 0.4 & 11.0 & 0.3 & 11.8 & 0.2 & 12.6 & 0.1 & 13.2 & 0.1 & 13.8 & 0.1 \\
\hline R11 & 10.1 & -0.1 & 11.0 & -0.2 & 11.8 & -0.2 & 12.6 & -0.3 & 13.2 & -0.3 & 13.7 & -0.4 \\
\hline Pentane & 9.8 & 2.6 & 10.7 & 3.0 & 11.5 & 3.4 & 12.2 & 3.8 & 12.8 & 4.2 & 13.3 & 4.5 \\
\hline $\begin{array}{l}\text { Iso- } \\
\text { pentane }\end{array}$ & 9.7 & 2.8 & 10.5 & 3.2 & 11.3 & 3.6 & 11.9 & 4.0 & 12.5 & 4.3 & 13.0 & 4.6 \\
\hline $\mathrm{R} 123$ & 9.8 & 0.5 & 10.7 & 0.6 & 11.4 & 0.6 & 12.1 & 0.6 & 12.7 & 0.5 & 13.1 & 0.5 \\
\hline $\mathrm{R} 245 \mathrm{ca}$ & 9.6 & 1.5 & 10.4 & 1.6 & 11.2 & 1.7 & 11.8 & 1.8 & 12.3 & 1.8 & 12.7 & 1.7 \\
\hline Cis-butene & 9.7 & -0.2 & 10.4 & -0.3 & 11.1 & -0.4 & 11.7 & -0.5 & 12.1 & -0.7 & 12.5 & -0.8 \\
\hline $\begin{array}{l}\text { Trans- } \\
\text { butene }\end{array}$ & 9.5 & 0.0 & 10.3 & -0.1 & 10.9 & -0.2 & 11.4 & -0.4 & 11.8 & -0.6 & 12.1 & -0.9 \\
\hline R245fa & 9.4 & 1.0 & 10.2 & 1.0 & 10.8 & 1.0 & 11.3 & 0.8 & 11.7 & 0.6 & 11.9 & 0.2 \\
\hline Butane & 9.3 & 0.8 & 10.0 & 0.8 & 10.6 & 0.7 & 11.1 & 0.6 & 11.5 & 0.3 & 11.7 & -0.2 \\
\hline Butene & 9.3 & -0.2 & 10.0 & -0.3 & 10.6 & -0.5 & 11.0 & -0.7 & 11.2 & -1.4 & & \\
\hline
\end{tabular}




$\begin{array}{lcccccccccc}\text { R114 } & 9.1 & 1.3 & 9.7 & 1.2 & 10.3 & 1.1 & 10.7 & 0.8 & 11.0 & 0.3 \\ \text { Isobutene } & 9.2 & 0.0 & 9.9 & -0.2 & 10.5 & -0.4 & 10.9 & -0.7 & 11.1 & -1.0 \\ \text { R236ea } & 9.0 & 1.8 & 9.7 & 1.8 & 10.2 & 1.8 & 10.6 & 1.5 & \\ \text { R142b } & 9.2 & -0.4 & 9.8 & -0.6 & 10.3 & -0.7 & 10.6 & -0.8 & \\ \text { Isobutane } & 8.9 & 0.5 & 9.5 & 0.3 & 10.0 & 0.0 & 10.3 & -0.5 & \\ \text { R236fa } & 8.6 & 1.0 & 9.1 & 0.6 & 9.4 & 0.1 & & & \\ \text { R124 } & 8.6 & -0.6 & 9.1 & -0.9 & 9.4 & -1.2 & & & \\ \text { R318 } & 8.0 & 4.4 & 8.4 & 3.7 & & & & & & \end{array}$


Table 9. Some properties of HFO1336mzzZ

\begin{tabular}{lccc}
\hline \multicolumn{1}{c}{ Parameter } & Value & Parameter & value \\
\hline Critical temperature & $171.3^{\circ} \mathrm{C}$ & ODP & 0 \\
Critical pressure & $2.9 \mathrm{MPa}$ & GWP & 9 \\
Latent heat at $298.15 \mathrm{~K}$ & $168.12 \mathrm{~kJ} / \mathrm{kg}$ & Boiling point & $33.4^{\circ} \mathrm{C}$ \\
Safety group (ASHRAE) & $\mathrm{A} 1$ & Molecular weight & $164 \mathrm{~g} / \mathrm{mol}$ \\
A, in Antoine Equation & 5.786889 & $\mathrm{M}$ & $1961.44, \mathrm{~kg} / \mathrm{m}^{3}$ \\
B, in Antoine Equation & 842.20 & $\mathrm{~N}$ & $608.99, \mathrm{~kg} / \mathrm{m}^{3}$ \\
$\mathrm{C}$, in Antoine Equation & -83.40493 & $\beta$ & 0.32 \\
\hline
\end{tabular}

Table 10. Thermodynamic parameters of HFO1336mzzZ at saturation state [48, 49]

\begin{tabular}{lccccccc}
\hline Parameter & \multicolumn{7}{c}{ Temperature, ${ }^{\circ} \mathrm{C}$} \\
\cline { 2 - 8 } & 30 & 100 & 110 & 120 & 130 & 140 & 150 \\
\hline$h_{l, s}, \mathrm{~kJ} / \mathrm{kg}$ & 233.9 & 325.35 & 338.73 & 353.52 & 369.72 & 385.21 & 402.82 \\
$h_{v, s}, \mathrm{~kJ} / \mathrm{kg}$ & 400.54 & 454.25 & 460.60 & 468.01 & 474.01 & 478.41 & 482.22 \\
$s_{l, s}, \mathrm{~kJ} / \mathrm{kg} / \mathrm{K}$ & 1.13 & 1.40 & 1.44 & 1.48 & 1.52 & 1.56 & 1.60 \\
$s_{v, s}, \mathrm{~kJ} / \mathrm{kg} / \mathrm{K}$ & 1.68 & 1.75 & 1.76 & 1.77 & 1.78 & 1.79 & 1.79 \\
$v_{v, s}, \mathrm{~m} / \mathrm{kg}$ & 6.19 & 49.3 & 58.63 & 82.67 & 102.33 & 134.3 & 179.9 \\
$p_{s}, \mathrm{MPa}$ & 0.09 & 0.72 & 0.89 & 1.18 & 1.42 & 1.69 & 2.03 \\
\hline
\end{tabular}


Table 11. Estimated efficiency of HFO1336mmZ compared with R245fa

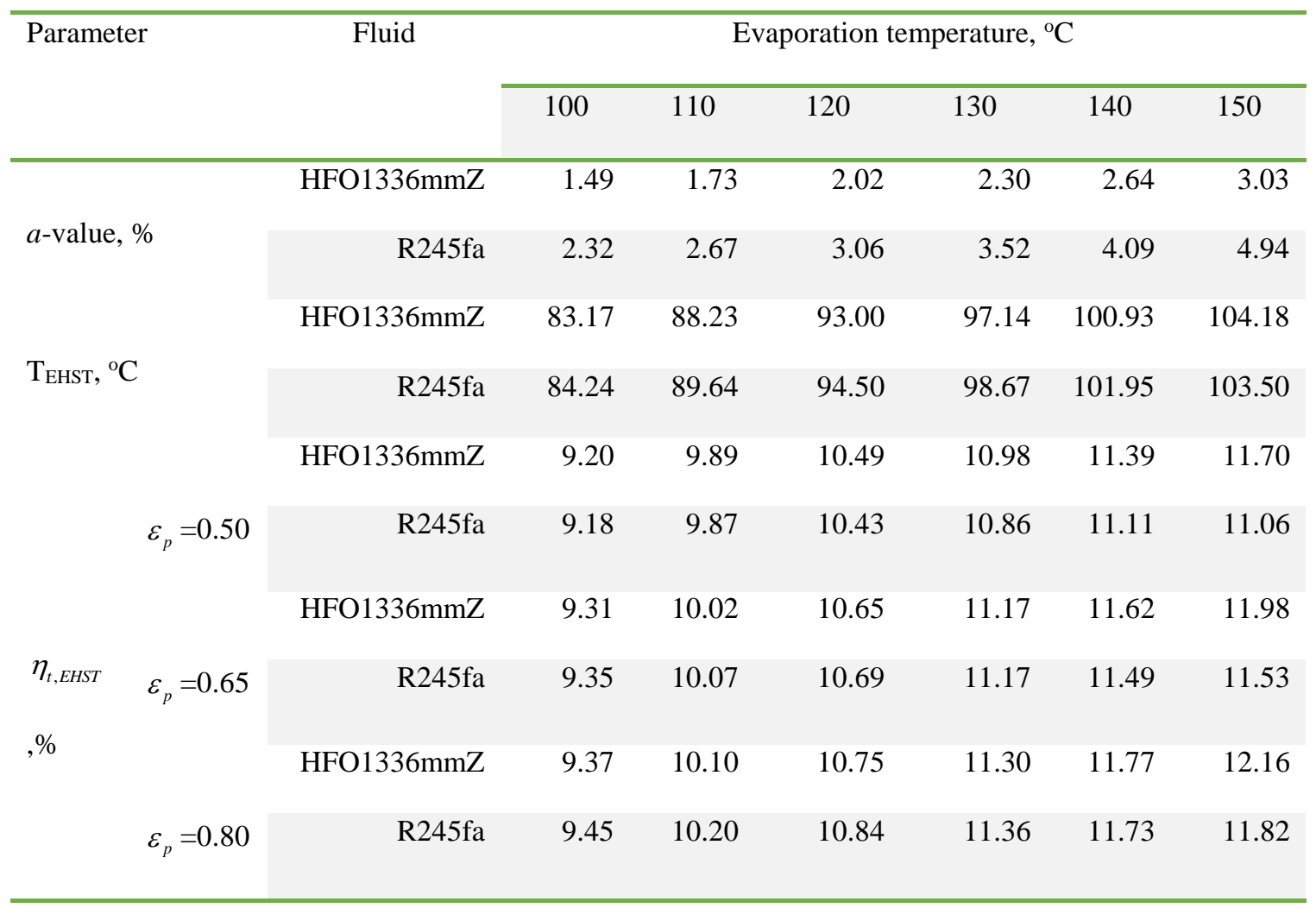




\begin{tabular}{|c|c|c|c|}
\hline \multicolumn{4}{|c|}{ Nomenclature } \\
\hline$a$ & ratio of pump power to expander power & EHST & equivalent hot side temperature \\
\hline$A-C$ & coefficients & FOM & Figure of Merit \\
\hline \multicolumn{4}{|l|}{$A^{\prime}-E^{\prime}$} \\
\hline$C$ & heat capacity, $\mathrm{kJ} / \mathrm{kg} \cdot \mathrm{K}$ & GWP & Global Warming Potential \\
\hline$h$ & enthalpy, $k J / k g$ & ODP & Ozone Depletion Potential \\
\hline$H v$ & vaporization latent heat, $\mathrm{kJ} / \mathrm{kg}$ & ORC & organic Rankine cycle \\
\hline$J a$ & Jacobs number & REFP & REFPROP \\
\hline$M$ & Coefficient & \multicolumn{2}{|c|}{ Subscripts/ Superscript } \\
\hline$N$ & Coefficient & $1-4$ & state points \\
\hline$P$ & pressure, $\mathrm{MPa}$ & $b p$ & boiling point \\
\hline$q$ & specific heat, $k J / k g$ & $c$ & critical \\
\hline$S$ & entropy, $\mathrm{kJ} / \mathrm{kg} \cdot \mathrm{K}$ & cond & condensation \\
\hline$T$ & temperature, ${ }^{\circ} \mathrm{C}$ & $e$ & expander \\
\hline$v$ & specific volume, $\mathrm{m}^{3} / \mathrm{kg}$ & $g$ & generator \\
\hline V & volume, $m^{3}$ & $i$ & input \\
\hline$w$ & specific work, $k J / k g$ & $i d$ & ideal \\
\hline \multicolumn{2}{|c|}{ Greek Symbols } & $L$ & liquid \\
\hline$\beta$ & Ising critical exponents & $o$ & output \\
\hline$\varepsilon$ & mechanic efficiency & over & overall \\
\hline$\eta$ & efficiency & $p$ & pressure/ pump \\
\hline$\mu$ & deviation & $r$ & reference \\
\hline$\rho$ & density, $\mathrm{kg} / \mathrm{m}^{3}$ & $S$ & isentropic/ saturated \\
\hline$\tau$ & Dimensionless temperature & super & super heat \\
\hline \multicolumn{2}{|c|}{ Abbreviation } & $t$ & thermal \\
\hline ECST & equivalent cold side temperature & $V$ & vapor \\
\hline
\end{tabular}

